Access to Play

for Children in

Situations of Crisis

Play: rights and practice

A toolkit for staff, managers and policy makers

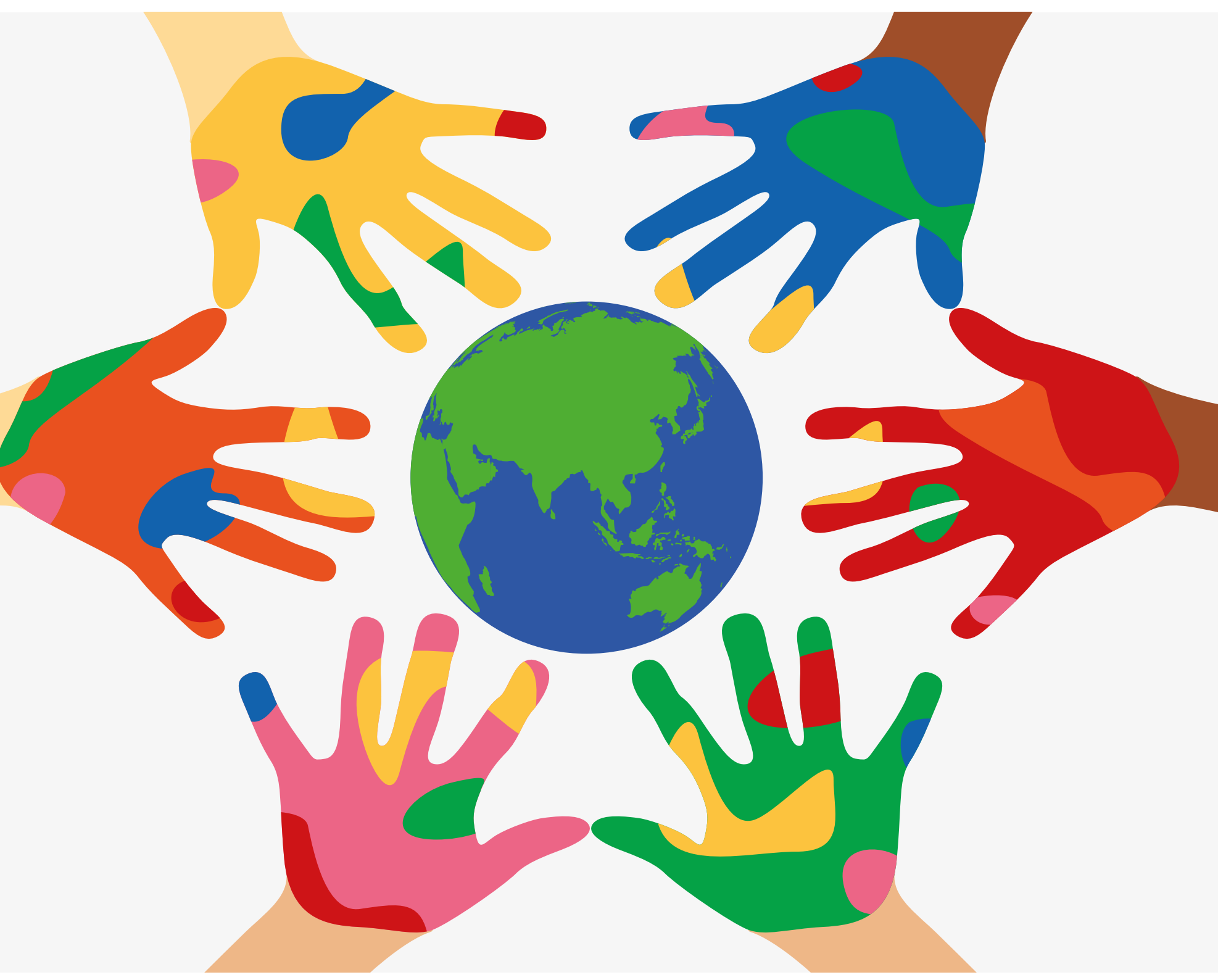

$1 \int_{\text {world }} \begin{aligned} & \text { International Play Association } \\ & \text { promoting the child's right to play }\end{aligned}$ 


\section{International Play Association}

promoting the child's right to play

\section{Editor}

Theresa Casey

\section{Writers}

Martin King-Sheard, Play Wales

Marianne Mannello, Play Wales

\section{Expert drafting groups}

Maria Assi, Beyond Association

Joseph Awad, Beyond Association

Millie Boswell

Theresa Casey, IPA Board

Sudeshna Chatterjee, IPA Consulting Project Officer

Cynthia Gentry, IPA Board

Mine Gol Güven, Bospherus University, Turkey

Gizem Kendik, Active Living Association, Turkey
Jess Milne, Halabja Community Play Project

Kay O’Brien, Oyster Training

Hitoshi Shimamura, IPA Japan

Karola Sakotnik, Red Noses International

Emergency Smile

Sule Serter, Active Living Association, Turkey

Dan Sykes

Kathy Wong, IPA Board

\section{Acknowledgements}

Active Living Association, Istanbul

Hackney Adventure Play Association, London

Angharad Wyn Jones, Play Wales

IPA Executive Board 2014-17

Dunkirk Children's Centre

Jack Awad
All participants in, and supporters of, the Access to Play in Crisis Special Workshop, Istanbul, 2014

All participants in the Access to Play in Crisis Researchers Meeting, New Delhi, 2016

\section{Honorary Patron: IPA Access to Play in Crisis}

Khder Kareem, Mayor of Halabja City, Vice-President of Mayors for Peace

(c) International Play Association: Promoting the Child's Right to Play. 2017. All rights reserved. 


\section{Contents}

\section{Introduction}

The toolkit

Using the toolkit

Key roles and responsibilities in situations of crisis

\section{Section 1: Information for Everyone Working in Situations of Crisis}

1 The right to play

2 The importance of play in situations of crisis

3 The features of an optimum environment for play

4 Understanding situations of crisis

5 Overcoming the challenges to playing in situations of crisis

6 The play rights of disabled children: an IPA position statement

\section{$\begin{array}{ll}\text { Section 2: Staff section } & 21\end{array}$}

Staff Tool 1 The importance of play 23

Staff Tool 2 The role of adults in supporting play in situations of crisis 24

Staff Tool 3 Responding to children's play - play clues and responses 26

Staff Tool 4 Types of play 29

Staff Tool $\mathbf{5}$ Play environments $\quad 30$

Staff Tool 6 More features of play environments for play 32

Staff Tool 7 Placemaking $\quad 33$

Staff Tool 8 Observing children's play $\quad 35$

Staff Tool 9 Resourcing play - loose parts 38

Staff Tool 10 Useful and basic play items 39

Staff Tool 11 Facilitating the beginning, middle and end of a play session 40

Staff Tool 12 Questions to support reflection/reflective practice 43

Staff Tool 13 Ethical considerations 45

Section 3: Managers section 47

$\begin{array}{lll}\text { Managers Tool } 1 & \text { Providing support to staff } & 49\end{array}$

Managers Tool 2 Providing induction about play 50

Managers Tool 3 Providing training to support play within programme activities 51

Managers Tool 4 Identifying and protecting environments for play 56

Managers Tool 5 Thinking about risk and challenge in play 58

Managers Tool 6 Spending donations for play 61

Managers Tool 7 Action planning $\quad 62$

Managers Tool 8 Working together 63

Managers Tool 9 Advocating for play 64

Section 4: Policy Makers section $\quad 65$

$\begin{array}{lll}\text { Policy Makers Tool } 1 & \text { Play policy } & 67\end{array}$

Policy Makers Tool 2 Models of provision 68

Policy Makers Tool 3 Working together to provide for the right to play in situations of crisis 74

Policy Makers Tool 4 Self-assessment tool: providing an optimum environment for play $\quad 75$ 


\section{Introduction}

\section{International Play Association: Promoting the Child's Right to Play (IPA) Access to Play in Crisis project}

IPA is an international non-governmental organisation founded in 1961. It provides a forum for exchange and action across disciplines and across sectors. IPA's purpose is to protect, preserve and promote children's right to play as a fundamental human right, as enshrined in article 31 of the United Nations Convention on the Rights of the Child.

IPA is concerned about the play rights of children experiencing difficult circumstances or challenging environments. Too many of the world's children face huge barriers in their everyday environments which mean that they must take their chances to play whenever and wherever they can - and sometimes in considerable danger. In situations of crisis, stress, weakened physical and emotional development, feelings of lack of control and loss of trust steadily multiply if children lack everyday opportunities for play.

Every aspect of children's lives is influenced by their need and desire to play; providing self-directed and self-determined opportunities to play can increase children's opportunities to build their own resilience.

Points of reference to ensure protection, participation and provision of play in situations of crisis.

- Play is a fundamental part of childhood

- Children's play is essential for healthy development and wellbeing

- It is a legitimate behaviour and a human right of all children

- In situations of conflict or disaster, opportunities for play have a significant therapeutic and rehabilitative role in helping children recover a sense of normality and joy after their experience of loss, dislocation and trauma

- Children's play spaces are important environments that should be protected and cared for

- We need to understand that children's idea of a desirable place to play may differ from that of an adult

- Adults should listen to what children say about playing and genuinely value their contributions

- We should protect children's time to play freely

- Agencies can support children by recognising the value playing brings to children's life experience and sharing that knowledge with others. 


\section{The toolkit}

This toolkit has been produced to support people and agencies working in crisis situations so that they are better able to understand and support children's everyday play. It defines situations of crisis as humanitarian, natural and man-made disasters.

The toolkit aims to support everyday, community-based play opportunities for children in crisis situations. It hopes to bring about change at two levels:

- the practical application of children's right to play for children in situations of crisis

- raised awareness of the right to play at a strategic level.

\section{It is designed to:}

- provide clear and concise information to individuals and organisations working with children and families in situations of crisis

- provide practical, step-by-step tools and templates for undertaking work linked to the provision of time, space, permission and materials for play

- be easy to print and photocopy so that it can be used to support activities in the field and for training and development.

The toolkit is underpinned by the recognition that children's play rights have a strong relationship with the UNCRC as a whole, supporting the realisation of all other rights.

\section{The UN Committee on the Rights of the Child (2013, para. 8) has said that article 31 serves to enrich the lives of children and is fundamental to:}

- the quality of childhood

- to children's entitlement to optimum development

- to the promotion of resilience

- to the realisation of other rights. 


\section{Using the toolkit}

\section{The toolkit is made up of four sections:}

- The first section is Information for everyone working in situations of crisis. This section includes information about the need to promote and provide for play in crisis situations. It should be read by staff, managers and policy makers

- The Staff section is for individuals working directly with children and young people in situations of crisis. It is designed to explain children's play and how adults can support it at practice level. By staff we mean both paid staff and volunteers

- The Managers section provides guidance for those responsible for children's services and people managing, supervising and training staff. It is designed to support these individuals to understand their role in supporting play

- The Policy Makers section provides guidance for non-governmental organisations (NGO's),

UN agencies, local, municipal and national governments. It presents a range of ways that services can be developed for children in situations of crisis. 


\section{Key roles and responsibilities in situations of crisis}

\section{Short-term staff}

Staff who work for a short period of time will need to be mindful that systems may have been put into place to support continuity.

\section{Their role includes:}

- creating and protecting space or time for play

- providing or making available resources to support or stimulate play

- actively facilitating play

- modelling positive attitudes to play and playing

- bringing a playful and creative approach.

\section{Medium to long-term staff}

Staff on site for longer than a few months will often build strong relationships with children and families.

\section{Their role includes:}

- developing quality play opportunities with children within the community

- enabling and supporting children to contribute to the development of play projects

- advocating for children's rights to play under the United Nations Convention on the Rights of the Child

- facilitating children's play through identifying, creating and protecting space and time for children to play, sourcing resources for children's play, directly facilitating play where appropriate, actively including children who would otherwise miss out on play or be excluded from activities

- identifying and taking action to remove barriers to play (social or physical). 


\section{Key roles and responsibilities in situations of crisis}

\section{Managers}

Managers are longer term staff supporting children and families and have an important role to play in supporting volunteers by:

- providing an induction period for all staff working directly with children

- providing training about play and how to support it

- providing on-going mentoring to help volunteers understand their role

- ensuring staff have time off and avoid burnout

- managing time, involvement of staff and transition periods.

\section{Policy makers}

Policy makers (NGOs, UN agencies, local, municipal and national governments) can promote the importance of play by embedding an approach that ensures that children in situations of crisis realise their right to play.

\section{This can be done by:}

- adopting a play policy such as the one in the Policy Makers section

- using the toolkit so that everyone involved is supported to understand his or her role

- ensuring that there are other policies (such as Volunteer Codes of Conduct and Child Protection) to support staff and volunteers who facilitate play opportunities. Regular training on the Child Protection policies and procedures should be provided for all who have direct access to children

- ensuring that staff has access to psychosocial support or training in psychosocial "first aid". This will support them to work with traumatised children in the immediate aftermath of a crisis

- whenever possible, providing for children's play from the outset and in the initial planning stages

- ensuring that other priorities do not negatively impact on children's access to play. 
Section 1:

Information

for everyone

working

in situations

of crisis 


\section{Section 1:}

\section{Information for}

\section{everyone working \\ in situations of crisis}

This section includes Information that everyone working in situations of crisis needs to know.

This section includes information about the need to promote and provide for play in crisis situations. It should be read by (staff, managers and policy makers.

Frequent mention is made of the Convention of the Rights of the Child (CRC) and General comment No. 17 (2013) on the right of the child to rest, leisure, play, recreational activities, cultural life and the arts (art. 31).

The Convention of the Rights of the Child can be found at:

http://ohchr.org/EN/Professionallnterest/Pages/CRC.aspx

The General Comment no. 17 can be found in English, Français, Español, русский中文, IJيüat:

http://tbinternet.ohchr.org/_layouts/treatybodyexternal/Download.

aspx?symbolno=CRC\%2fC\%2fGC\%2f17\&Lang=en

IPA has produced a summary of United Nations General comment No. 17:

http://ipaworld.org/childs-right-to-play/article-31/summary-gc17

\section{Section contents}

1 The right to play

2 The importance of play in situations of crisis

3 The features of an optimum environment for play

4 Understanding situations of crisis

5 Overcoming the challenges to playing in situations of crisis

6 The play rights of disabled children: an IPA position statement 


\section{The right to play}

The importance of play is recognised and enshrined in the Convention on the Rights of the Child (CRC) of 1989. It explicitly states in article 31 that:

"States Parties recognise the right of the child to rest and leisure, to engage in play and recreational activities appropriate to the age of the child and to participate freely in cultural life and the arts." (UN General Assembly, 1989)

As an indication of the significance the United Nations places on children's play it published General comment No. 17 on article 31. This helps everyone with an interest in the wellbeing of children to better understand the importance of play.

Play: Children's play is any behaviour, activity or process initiated, controlled and structured by children themselves; it takes place whenever and wherever opportunities arise.

Caregivers may contribute to the creation of environments in which play takes place, but play itself is non-compulsory, driven by intrinsic motivation and undertaken for its own sake, rather than as a means to an end.

Play involves the exercise of autonomy, physical, mental or emotional activity, and has the potential to take infinite forms, either in groups or alone. These forms will change and be adapted throughout the course of childhood.

The key characteristics of play are fun, uncertainty, challenge, flexibility and non-productivity. Together, these factors contribute to the enjoyment it produces and the consequent incentive to continue to play.

While play is often considered non-essential, the Committee reaffirms that it is a fundamental and vital dimension of the pleasure of childhood, as well as an essential component of physical, social, cognitive, emotional and spiritual development. 
Children in situations of crisis may have access to other specific services with a clear and structured outcome (i.e. health or education services); however, for children to benefit the most from play, their play behaviour as far as possible is:

- Freely chosen - children choose how, what and with whom they play

- Personally directed - wherever possible, children should be in control of 'how' they play

- Intrinsically motivated - playing happens for its own sake and not for an external goal or reward.

- In a secure context - that the child has confidence that any real threat or danger to them has been minimised.

Article 31 must be understood holistically, both in terms of its constituent parts and also in its relationship with the Convention in its entirety. Each element of article 31 is mutually linked and reinforcing, and when realised, serves to enrich the lives of children. Together, they describe conditions necessary to protect the unique and evolving nature of childhood. Their realization is fundamental to the quality of childhood, to children's entitlement to optimum development, to the promotion of resilience and to the realization of other rights. Indeed, environments in which play and recreational opportunities are available to all children provide the conditions for creativity; opportunities to exercise competence through self-initiated play enhances motivation, physical activity and skills development; immersion in cultural life enriches playful interactions; rest ensures that children have the necessary energy and motivation to participate in play and creative engagement.

(Committee on the Rights of the Child, 2013: para. 8) 


\section{The importance of play in situations of crisis}

The Committee on the Rights of the Child has expressed a deep concern, that in situations of conflict or disaster children's right to play is often given lower priority than the provision of food, shelter and medicines. This is despite the fact that play is known to be crucial to children's wellbeing, development, health and survival in these circumstances.

"Children have a spontaneous urge to play and participate in recreational activities and will seek out opportunities to do so in the most unfavourable environments. However, certain conditions need to be assured, in accordance with children's evolving capacities, if they are to realise their rights under article 31 to the optimum extent."

(Committee on the Rights of the Child, 2013:10)

\section{It notes that in these situations, playing:}

- has a significant therapeutic and rehabilitative role in helping children recover a sense of normality and joy after their experience of loss, dislocation and trauma

- helps refugee children and children who have experienced bereavement, violence, abuse or exploitation, to overcome emotional pain and regain control over their lives

- can restore a sense of identity, help them make meaning of what has happened to them, and enable them experience fun and enjoyment

- offers children an opportunity to engage in a shared experience, to re-build a sense of personal value and self-worth, to explore their own creativity and to achieve a sense of connectedness and belonging. 


\section{The features of an optimum environment for play}

The Committee on the Rights of the Child asserts that children have a spontaneous urge to play and participate in recreational activities and will seek out opportunities to do so in the most unfavourable environments. However, certain conditions need to be assured, in accordance with children's evolving capacities, if they are to realise their rights under article 31 to the optimum extent.

\section{As such, children should have:}

- Freedom from stress

- Freedom from social exclusion, prejudice or discrimination

- An environment secure from social harm or violence

- An environment sufficiently free from waste, pollution, traffic and other physical hazards to allow them to circulate freely and safely within their local neighbourhood

- Availability of leisure time, free from other demands

- Accessible space and time for play, free from adult control and management

- Space and opportunities to play outdoors unaccompanied in a diverse and challenging physical environment, with easy access to supportive adults, when necessary

- Opportunities to experience, interact with and play in natural environments and the animal world

- Opportunities to invest in their own space and time so as to create and transform their world, using their imagination and languages

- Opportunities to participate with other children, supported, where necessary, by trained facilitators or coaches

- Recognition by parents, teachers and society as a whole of the value and legitimacy of the rights provided for in article 31. (Committee on the Rights of the Child, 2013:10-11).

The lack of play impacts on all children wherever they live. Children living in poor or hazardous environments, children in situations of conflict or humanitarian disaster, asylum-seeking and refugee children, children in street situations, and migrant or internally displaced children are likely to be unreasonably affected by environmental constraints on their enjoyment of their right to play. Policy makers who are sensitive to children's play needs in the planning, design and management of programmes to support such children will create more desirable environments and alleviate the possible effects of lack of play. 


\section{Understanding situations of crisis}

Globally profound disaster conditions - both natural and man-made - are on the rise precipitating situations of crisis of different scales and nature. (See Table 1 for a typology of crisis). Large-scale disasters can intensify or increase the frequency of small disasters and everyday hazards. Everyday hazards can have as great or sometimes greater impact on children's lives over the long run than a one-time large-scale disaster but are commonly left out of discussions of disasters. It is for this reason this toolkit includes everyday hazards in the framework of typology of crisis situations.

Situations of crisis include the following contexts: man-made conflicts such as war, acts of terrorism, forced migration and displacement, refugees and refugee camps; and natural disasters, which are disaggregated by climate and non-climate-related events and persistent everyday hazards. Extreme climate-related natural disasters include storms, floods, extreme temperature, drought, and wildfire.

Non-climate-related natural disasters consist primarily of geophysical events such as earthquakes, volcano eruptions, and tsunamis. Some biological disasters (epidemics, insect infestations, animal stampedes) also qualify as natural disasters and can fall in either climate-related or non-climaterelated categories (UNCDSN 2016).

\begin{tabular}{|c|c|c|c|}
\hline $\begin{array}{l}\text { Nature } \\
\text { of event }\end{array}$ & $\begin{array}{l}\text { Large Scale Natural and } \\
\text { Humanitarian Disasters } \\
\text { (e.g. tsunamis, earthquakes, } \\
\text { typhoons, civil wars, genocide, } \\
\text { international conflicts, drought) }\end{array}$ & $\begin{array}{l}\text { Small Disasters } \\
\text { (e.g. seasonal flooding, } \\
\text { storms, house fires, } \\
\text { localised landslides, } \\
\text { wildfire, epidemics) }\end{array}$ & $\begin{array}{l}\text { Everyday Hazards } \\
\text { (e.g. unsafe, hazardous } \\
\text { living environments, } \\
\text { preventable disease, traffic) }\end{array}$ \\
\hline Frequency & $\begin{array}{l}\text { TYPICALLY, INFREQUENT } \\
\text { THOUGH COMMON TO SOME } \\
\text { PARTS OF THE WORLD }\end{array}$ & $\begin{array}{l}\text { FREQUENT } \\
\text { (seasonal) }\end{array}$ & EVERYDAY \\
\hline Scale & $\begin{array}{l}\text { LARGE or potential to be } \\
\text { large and life threatening }\end{array}$ & MEDIUM & $\begin{array}{l}\text { MEDIUM in inadequate } \\
\text { living environments }\end{array}$ \\
\hline $\begin{array}{l}\text { Impact on } \\
\text { children }\end{array}$ & $\begin{array}{l}\text { Can be catastrophic, } \\
\text { violating basic rights } \\
\text { of the child }\end{array}$ & $\begin{array}{l}\text { Significant but under- } \\
\text { estimated contribution } \\
\text { to children's ill-health, } \\
\text { injuries, loss of wellbeing }\end{array}$ & $\begin{array}{l}\text { Significant and mostly } \\
\text { ignored contributor to } \\
\text { creating unfavourable living } \\
\text { environments for children }\end{array}$ \\
\hline Risks & INTENSIVE RISKS & EXTENSIVE RISKS & $\begin{array}{l}\text { EXTENSIVE RISKS } \\
\text { IN SOME PLACES } \\
\text { AND TIMES }\end{array}$ \\
\hline
\end{tabular}

Typology of Crisis Situations and Risk Spectrum was developed by Sudeshna Chatterjee for the IPA Access to Play in Crisis research projects. 


\section{Overcoming the challenges to playing in situations of crisis}

Impacts across both natural and man-made events are often consistent, with community displacement and disparate or uncoordinated responses key features. There is often a consistent lack of recognition of the importance of play, which can result in a limited response in terms of resources.

The following issues can apply to both natural events and man-made conflict:

- Population relocation

- Loss of hope

- Exploitation by business

- No political will to address the crisis

- Internal and external prejudice

- Lack of resources
- Lack of recognition of play and its importance

- Disparate approaches

- Lack of understanding of cultural issues

- Family issues

- Hostile and unsafe physical environments.

\section{Examples of challenges

Location and characteristics

Unhealthy and

unsafe spaces

Unhygienic spaces

Physical hazards (rubbish, broken glass, diseased animals)
- Identify hazards in the local environment in partnership with the community and children while selecting safe spaces for children's use (in many programmes, children are actively engaged in Hazard Vulnerability Analysis (HVA) through their clubs to monitor and improve their living conditions)

- Site selection must consider the communicable disease environment (e.g. prevalence of malaria due to open still water sources in hot-humid climates)

- Play spaces and general areas need to be regularly cleaned to create a sense of freedom and safety

- Consider physical alterations, which may need to be made to improve environmental health (i.e. restricting access to fast flowing water, areas of standing water which may provide breeding places for mosquitoes and road systems). 
Monotony

Life in temporary camps/ shelter can be repetitive and unstimulating
- Provide a diverse range of play materials and a space to use them

- Consider a space that is protected from extreme weather and secure so that the resources can be used for playing

- Provide low cost play items for children to take to their living space. 'Play boxes' can be created with easy to source play materials, which can be used in a number of ways. These will support children to play when organised play opportunities are not available

- Provide information about play for parents in these boxes will promote the importance of play and encourage play in or near living spaces

- Toys may have increased value in the eyes of children and their families as they may have few of their own possessions. If toys are to be provided to individual children care must be taken to ensure that these do not become items that can lead to conflict between children and families.

\section{Location}

Poorly located play space

- Accessible safe play space should feature as a key consideration when planning and building sites to support communities in situations of crisis

- Locate play spaces in the heart of the community/camp ideally near community services

- When suitable sites are multi-use spaces, portable play spaces with secure play storage boxes may be considered for temporal use of the site

- Organise visits from local mobile play provision to set up play spaces

- Climate considerations for temporal spaces, particularly tents which are used as child friendly spaces where children play:

- Hot climate: a tent may provide much needed shade

- Cold climate: tents are at risk of collapse from snowfall and may need reinforcing

- Wet climate: tents at risk from flooding (use sandbags/raised floor) or collapse from rainfall and need weather-proofing (use plastic sheet to keep rain off).

Space for supervising parents
- Provide shade

- Provide space for their own social activities

- Provide privacy for taking care of the needs of their children.
Lack of space for creative activities (for all)
- Indoor and informal spaces (sheds, family centres) where adults can be creative and children can benefit time to play and socialise. 


\section{Examples of challenges A range of possible actions}

\section{Constraints on time}

Parents busy with other

- Supervised spaces where children can play.

issues and not allowing

children to play outdoors

Parents with negative

- Training programme/activities for parents that promote the importance views of play and playing of play and address parental fears or prejudices

- Staff can meet parents to build trust and get to know the community.

Freedom of expression and emotional regulation

No place for children to express full range of emotions
- Identify and providing a space, which is separate from the high density of a site, will help children to express themselves

- Staff understand children's play, play behaviour and how to support and provide for it

- Staff provide a range of options (such as access to creative activities, structured recreation) to encourage expression.

Cultural sensitivity

Gender/religious
- Staff must ensure that they understand the cultural needs of the community and how this impacts on play

- Programmes should provide information for staff/volunteers, providing training and mentoring when time allows

- Community consultations should be undertaken to understand and address some problematic issues, such as:

- Girls and boys playing together

- Girls playing publicly

- Proximity to toilets

- Proximity to dark/closed in spaces. 


\section{The play rights of disabled children: an IPA position statement}

IPA believes that every child must be afforded equal opportunities to enjoy his or her right to play in their everyday lives. Disabled children have the same right as other children to sufficient time and space to play freely, in the ways that they choose, without being unduly overprotected.

Many disabled children face multiple barriers that restrict their day-to-day opportunities to play. These barriers include the imposition of adult-decided activities, inaccessible facilities and environments, negative attitudes and inappropriate social policies and programmes which restrict the lives of disabled children.

IPA believes that families, care-givers, professionals and authorities must recognise the value of play, both as a right in itself and a means of achieving optimum development. Every child is different and to enable each child to enjoy their right to play, pro-active measures are needed to remove disabling barriers and promote accessibility, such as:

- awareness raising amongst adults and peers

- age-appropriate support or assistance

- accessible and inclusive environments, facilities and transport

- provision of information, education and training which support children's right to play.

IPA strongly endorses the view of the UN Committee on the Rights of the Child that play is a fundamental and vital dimension of the pleasure of childhood, as well as an essential component of physical, social, cognitive, emotional and spiritual development. IPA therefore seeks to protect, preserve and promote disabled children's right to play as expressed in article 31 of the UN Convention on the Rights of the Child (UNCRC).

IPA wishes to draw attention to article 23 of the UNCRC and articles 7 and 30 of the UN Convention on the Rights of Disabled Persons which further encompass disabled children's play rights. Children have told us that their lives would be happier and healthier if Governments took children's right to play seriously. IPA fully endorses this view.

\section{References}

Committee on the Rights of the Child (2013) General comment No. 17 (2013) on the right of the child to rest, leisure, play, recreational activities, cultural life and the arts (art. 31). Children participating in the making of IPA child-friendly article 31 posters (2013).

\section{A note on terminology}

The form of wording 'disabled children' used here is understood to recognise the social model of disability developed by disabled people, rather than the medical model of disability which locates the disability as a problem with the individual. Briefly, within the social model to be disabled refers to the discrimination experienced by children and adults on the grounds of their impairment(s). Practices which exclude and discriminate appear as social, environmental or organisational barriers which serve to exclude certain people. However, the 'people first' movement tends to prefer the use of phrases such as 'children with disabilities' and this is also the form used in the documents of the UN Committee on the Rights of the Child (the Convention, General comments etc.). In this paper, we have used the former however understand others will prefer other forms. They key message remains the same. 
Section 2: Staff section 


\section{Section 2 \\ Staff section}

This section is for individuals working directly with children in situations of crisis.

It is designed to explain children's play and how adults can support it at practice level.

\section{It provides tools, which help staff to:}

- create a space for play

- protect safe space or time for play

- provide or make available resources to support or stimulate play

- actively facilitate play.

\section{Section contents}

Staff Tool 1 The importance of play

Staff Tool 2 The role of adults in supporting play in situations of crisis

Staff Tool 3 Responding to children's play - play clues and responses

Staff Tool 4 Types of play

Staff Tool 5 Play environments

Staff Tool 6 More features of play environments for play

Staff Tool 7 Placemaking

Staff Tool 8 Observing children's play

Staff Tool 9 Resourcing play - loose parts

Staff Tool 10 Useful and basic play items

Staff Tool 11 Facilitating the beginning, middle and end of a play session

Staff Tool 12 Questions to support reflection/reflective practice

Staff Tool 13 Ethical considerations 


\section{Staff Tool 1 \\ The importance of play}

Playing is central to children's physical, mental, social and emotional health and wellbeing and is enshrined in the United Nations Convention on the Rights of the Child (UNCRC). Through play, children develop resilience and flexibility and for children themselves, playing is one of the most important aspects of their lives (IPA, 2010).

Playing can provide regular physical activity, which helps prevent diseases and relieves depression and anxiety. Playing is strongly linked to creativity - it involves imagination and problem solving.

Play is a natural, active and often unplanned process in which thinking, feeling and doing can flourish; when children are playing, they are able to be inventive and creative. Children benefit greatly through having regular opportunities to play in familiar settings, which provide time, space and permission for play.

Play helps young children to learn and develop skills through doing and talking and is the way they learn to think. It is also how they learn to socialise, as children engage with other children and adults. For older children, playing provides time to relax, explore the world and to spend time with other people and socialise with friends.

Playing helps children to make sense of their experiences and their world. Providing space and time for play supports them to re-enact and repeat events. Playing out their own feelings and dreams helps children come to terms with them and achieve a sense of control. They can safely express anger and aggression without harming people, or without it harming them.

Play is a vital element in children's development and can be a strong protective factor in children's lives. It can, to an extent, shield children from the negative aspects of situations of crisis. It allows them to develop their inner resources and build resilience to the difficulties and uncertainties they experience through crisis. 


\section{Examples}

\section{Wait to be invited to play.}

- Staff are sensitive and careful not to take over; they organise play activities only when children want them to

\section{Enable play to occur uninterrupted.}

- Staff think hard before they organise too much or interrupt the flow of play

\section{Enable children to explore their own values.}

- Supporting play requires a sensitive, flexible approach which recognises that children explore and understand value systems through playing and sometimes making mistakes

\section{Leave children to develop skills at their own pace.}

- Play is a mechanism where children develop their own skills, abilities and judgement. Staff are conscious of allowing children to manage at their own pace and to learn through trial and error

\section{Leave the content/intent of play to the children.}

- Play is an integral part of the child's experience of the world. Within safe limits, how it is done is a matter for them - it is their agenda

\section{Let children decide why they play.}

- Play is behaviour without goals or rewards. It is a process. No prizes or inducements need be offered

\section{Enable children to decide what is appropriate} behaviour, within safe limits.

- The play space should exist for the children's benefit. Play settings may need guidelines but they do not need complex rules

\section{Only organise when children want support.}

- Children sometimes run out of inspiration and become bored, and they may ask for help inventing something to do or to find resources they need.

\section{Thinking about our responses to children's play}

We should aim to get directly involved in children's play only when we are invited by them or when we have concerns about their safety.

\section{A good way to think about this is to:}

STOP yourself before you respond to, or stop, children's play

LOOK AND LISTEN to what is happening. What are children doing?

THINK - Are children managing any risks? What might be the impact of adult involvement on children's play?

ACT - Now you can respond in a thoughtful way, rather than by reflex.

REFLECT - Was your action the correct one? What have you learned? 


\section{Staff Tool 3 \\ Responding to children's play - play cues and responses}

Adults can gain a better understanding of children's play by looking out for play 'cues' and responding appropriately. A play cue can be verbal, a gesture or an action and invites others to join the play. A response to a play cue creates a play frame.

Children generally respond to each other's play cues naturally but for adults, understanding and recognising play cues is a useful skill to ensure we respond appropriately to children's play.

A play cue is a lure or an invitation to someone, or something to 'play with me'. Children communicate far more with their bodies than with verbal sentences.

A cue can be:

- an action

- a facial expression

- a gesture

- a look

- a posture

- a stance

- a sound

- tap on shoulder and run away laughing.

The return is a positive and equally playful response to a recognised cue, which can also act as a further cue - an indication to take the play further. Returns are usually from people (mostly other children) but can also be from the environment or things in the environment.

The frame can be:

- physical - a place or space, which could be as small as a cardboard box or as large as a playing field and which might be visibly indicated by mats, stones, rope, tyres, clothes, a hedge or fence, or a structure, platform, den, room or corridor

- narrative - a brand new or a time-honoured storyline, a song or a piece of music, or a set of agreed rules. Any of these can give the reason for playing and hold the play together

- emotional - when play is exploring a feeling such as fear, grief or triumph, so the props, the action, the place and the story can keep changing because it's the experience of the feeling that holds it all together. 


\section{Cue}

the invite

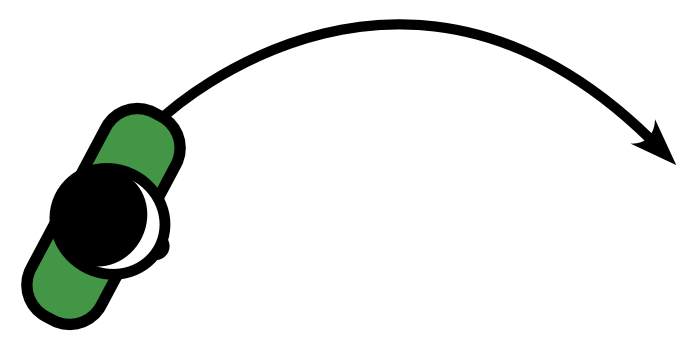

\section{Return}

the response

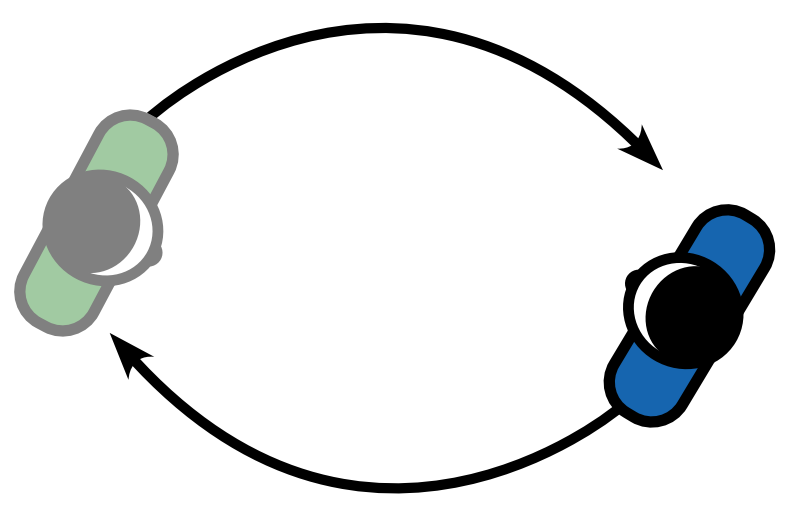

\section{Frame}

the natural or created 'boundaries of the play that hold it together

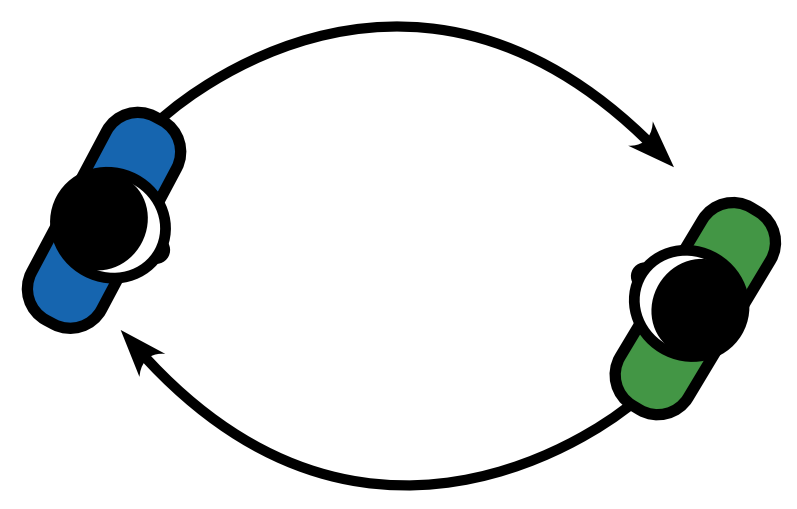




\section{Adults can respond to play cues by:}

\section{Joining in with play when invited}

We should be sensitive to children's requests for our involvement, as children should be enabled to play without adult direction. However, sometimes we are directly invited to play and this can be a good opportunity for positive interactions with children.

\section{Examples of invitations to play may include:}

- a direct verbal request ("Play with me"!)

- a playful action (throwing something, poking)

- a facial expression (smile, funny faces)

- an indirect verbal cue ("I can’t do it”! Or "This is boring"!).

\section{Providing resources that respond to play cues}

If we observe children playing with each other it can provide us with clues about resources to provide. If, for example, children are involved in role play (you be the doctor!) dressing up, fabrics or other small loose parts may help them to extend their play.

\section{Not taking over}

We should be very careful not to take over in response to children's play cues. If a child is saying they are bored, our response should be to support them to come up with ideas or to start a game but be mindful to not overly direct. If children want to adapt the rules that is fine. If children have clearly become engaged in the game or activity we have set up we should be take a step back until we are needed.

\section{Adults can support children's play cues by:}

\section{Responding to misunderstood cues}

Some children will misinterpret other children's play cues because they are aggressive, out of context or unwelcome. We can support children by modelling appropriate play cues and providing alternative play opportunities. For example, when playing a game of chase a child may hit another child too hard rather than with a light tap. By recognising this as a play cue rather than aggressive behaviour we can model more appropriate ways of playing.

\section{Allocating a secure space for play}

By allocating a space for play with supportive, understanding adults, we can enable children to experiment with different ways of responding to each other's cues.

\section{Recognising subtle play cues}

Play cues may not be obvious and could be no more than a glance or small action. The more we observe children's play, the better we get at recognising cues.

\section{Understanding that play cues may not be to other people}

Children's play cues can be to their environment or things within it. This can be hitting something to make a noise, destroying something they've created or changing its appearance by painting or remodeling. This is part of children learning about the things around them and we can support this process by ensuring resources we provide allow for this kind of experimentation without causing unnecessary damage to things that are valued by others. 


\section{Staff Tool 4 Types of play}

By observing children's play and reflecting on the types of play we see, we can come to a better understanding about the children's play needs and preferences.

Hughes (2001) provides a model for reflecting on the ways children play by describing observable types of play.

Whilst children may not necessarily display all the play types, if children seem to only be playing in ways which demonstrate a small group of play types, this may alert adults to widen the opportunities available to children. For example, if there is a clear dominance of deep play, rough and tumble and locomotor play, the children may benefit from the opportunity to engage in creative play, imaginative play and object play.

\section{Communication Play}

Example: songs, mime, jokes, facial expression (the play face), clapping games, gestures, and poetry.

\section{Creative Play}

Example: where children have access to lots of different creative mediums and tools, where there is plenty of time and where getting messy is not a problem.

\section{Deep Play}

Example: children playing in a way that might threaten their life; in front of traffic, riding a bike on the parapet of a bridge or through a fire, high tree climbing, especially over rivers or the sea.

\section{Dramatic Play}

Example: a dramatisation of parents taking children to school, of a TV show, of a conversation between two people, of a religious or festive event, a funeral.

\section{Imaginative Play}

Example: patting a dog that isn't there, eating food that doesn't exist, or singing into a non-existent microphone.

\section{Locomotor Play}

Example: chase, tag, running, hide and seek, off-ground touch and tree climbing.

\section{Object Play}

Example: examination and novel use of almost any object, such as a ball, a marker, a piece of cloth, even live or dead animals.

\section{Rough and Tumble}

Example: play fighting, wrestling and chasing, where children involved are laughing and squealing and from their facial expressions obviously enjoying themselves.

\section{Social Play}

Example: building or painting something together, co-operatively moving/carrying something, informal team games, or parachute games.

\section{Symbolic Play}

Example: using an object like a piece of wood to symbolise a person or a flag to symbolise a group or tribe. 


\section{Staff Tool 5 \\ Play environments}

To understand what could be offered, it is important to consider the local environment in which children play. Given time, space and permission to play, children will naturally choose to play wherever and whenever they wish. What is available to children can be assessed against how children need to play.

Auditing the environment provides a process to identify how it is, or isn't, meeting children's play needs and to identify possible actions.

Safeguarding space for play: environments for play do not always look pretty or appealing to adults. While it is important to identify hazards in the environment and mitigate those where possible, it is also important for adults to do all they can to see the environment through the eyes of the child. Use this tool in conjunction with Staff Tool 4.

\begin{tabular}{|c|c|c|}
\hline $\begin{array}{l}\text { What does the play environment offer } \\
\text { for play? (Affordance in the environment) }\end{array}$ & $\begin{array}{l}\text { Note examples } \\
\text { or description here }\end{array}$ & $\begin{array}{l}\text { Suggested actions to } \\
\text { supplement or enhance } \\
\text { with resources, design } \\
\text { or other intervention }\end{array}$ \\
\hline $\begin{array}{l}\text { Is it varied and interesting? (e.g. flat } \\
\text { smooth surfaces for playing games, slopes } \\
\text { for rolling down etc.; are there features - } \\
\text { not necessarily intended for play - } \\
\text { such as trees, statues, landmarks) }\end{array}$ & & \\
\hline $\begin{array}{l}\text { Does it offer challenge? (e.g. features for } \\
\text { jumping over, jumping down from, swinging } \\
\text { on, hanging from, climbing on) }\end{array}$ & & \\
\hline $\begin{array}{l}\text { Does it offer opportunities to play with the } \\
\text { natural elements? Earth, water, fire, air? }\end{array}$ & & \\
\hline
\end{tabular}

Note: Depending on the situation and specific needs of the children, the relative proportions of the matrix may vary. 
What does the play environment offer for play? (Affordance in the environment)
Note examples

or description here
Suggested actions to supplement or enhance with resources, design or other intervention

Does it offer opportunities to manipulate natural and fabricated materials? (e.g. loose parts for building, digging, throwing, moulding)

Does it provide sensory stimulation? (e.g. sights, sounds and smells of streets, temples etc., planting in parks, seasonal changes in trees and landscape)

Does it support social interactions?

(e.g. places for hiding, peace and quiet, secret places, private places, places for looking out from, places to find friends and playmates)

Does it offer opportunities to experience a range of emotions? (e.g. by offering gathering places and places for group play, places for quiet or solitary play)

Note: Depending on the situation and specific needs of the children, the relative proportions of the matrix may vary. 


\section{Staff Tool 6 \\ More features of play environments to consider}

Other children - of different ages and abilities with a choice to play alone or with others, to negotiate, co-operate, fall out, and resolve conflict. In situations of crisis, establishing relationships with each other may be a challenge. There may be a high turnover with families arriving and leaving meaning that social groups and group dynamics are changing.

The natural world - weather, trees, plants. Children may find themselves in unsafe physical environments with many hazards and poor conditions. In situations where there may be some limited access to nature or a natural feature, every effort should be made to ensure children have access to use this for their play.

The four elements - earth, air, fire and water. Access to the elements takes on a new meaning in situations of crisis and children may be freely experiencing these with little or no support from staff. If access is identified as lacking for children, there are some creative ways to provide supervised experiences for children that don't create unnecessary pressures for parents/families who will not have access to spare clothes and laundering facilities.

- fire - provide fire buckets for small fires, indoor cooking and candle making

- water - create opportunities to play safely with water, such as water slides, paddling pools, splashing and chasing games

- air - access to air can come in the form of flying kites, making windmills, watching the effect of wind on trees and water

- earth - pottery and gardening give children access to earth. If there are earth banks, children will inevitably want to dig holes and caves. When this happens, it is important to help children do this safely.

Loose parts - natural and man-made materials that can be manipulated, moved and adapted, built and demolished. Although loose parts are important, the logistics of sourcing and storage may be challenging for staff working in crisis situations. In some situations, loose parts will be plentiful whilst in others they may have practical value for purposes other than play, staff will need to consider how to manage these factors.

Challenge and uncertainty - graduated opportunities for risk taking; both on a physical and emotional level.

Changing identity - role-play, dressing up, mirrors, face paints, make-up, cameras and video can all facilitate exploration of identity.

Movement - running, jumping, climbing, balancing, rolling, swinging, sliding and spinning.

The senses - sounds, tastes, textures, smells and sights should all be stimulated. Music, food, perfumes, colours, views and different textures do that. 


\section{Staff Tool 7 Placemaking}

Consider how you will define and secure a place for children to play if there isn't a designated space. In an outdoor area, you could define a space using:

- a rope on the ground

- a circle of stones or logs

- a blanket or a shower curtain
- a chalk circle

- a flag or banner

- a shelter.

Sounds such as a bell, music, loud hailer, drums or whistles will attract children to a play space.

Tents, shelters, banners, balloons and flags will create a focal point and provide a message to the wider community that play is important and necessary for children.

Do not underestimate the importance of a trusted adult in creating a space for play. Sometimes the presence of that adult, there to support play, is all that is required to indicate that play can happen there.

In an indoor area, you may be in a shared building with other services, consider marking the space for playing with:

- a curtain

- furniture

- tarpaulin

- rope.

- parachute

Whilst it is important to be sensitive to the other services operating in the space, it is also important that they value and recognise the important contribution that playing makes to overall child wellbeing.

Sometimes, sharing a space helps others recognise how important a play service is and these colleagues can help you to secure a more appropriate place for playing. 


\section{Steps to take}

- Think of ways to let children and families know where you will be and what you will be doing

- Joining an existing service may help you to gain access and trust

- Identify and remove hazards in the general space and wider environment

- Remove litter, broken glass, redundant signs, etc

- If there are places nearby (such as bushes or the back of buildings) where children may hide and play, be sure to check these for hazards

- Regularly clean these spaces and general areas to create a sense of freedom and safety

- Look at physical alterations which may need to be considered (i.e. restricting access to flowing water, road systems)

- Make sure that any supervision of hazardous areas does not restrict playing but limits hazard
- Look at how you can make alterations to the area to ensure disabled children or children with impairments can take part as equally as possible

- Make sure the play materials are suitable for the area available

- If the site changes, make sure children and families know where you will be. Don't rely just on word of mouth, use posters and signs for instance

- Try to maintain some level of stability with timings

- Try to ensure the area has a playful and fun atmosphere

- Try to incorporate quiet areas as well

- Be clear that the purpose is to provide for play for children - there is no sectarian, political or religious purpose behind it.
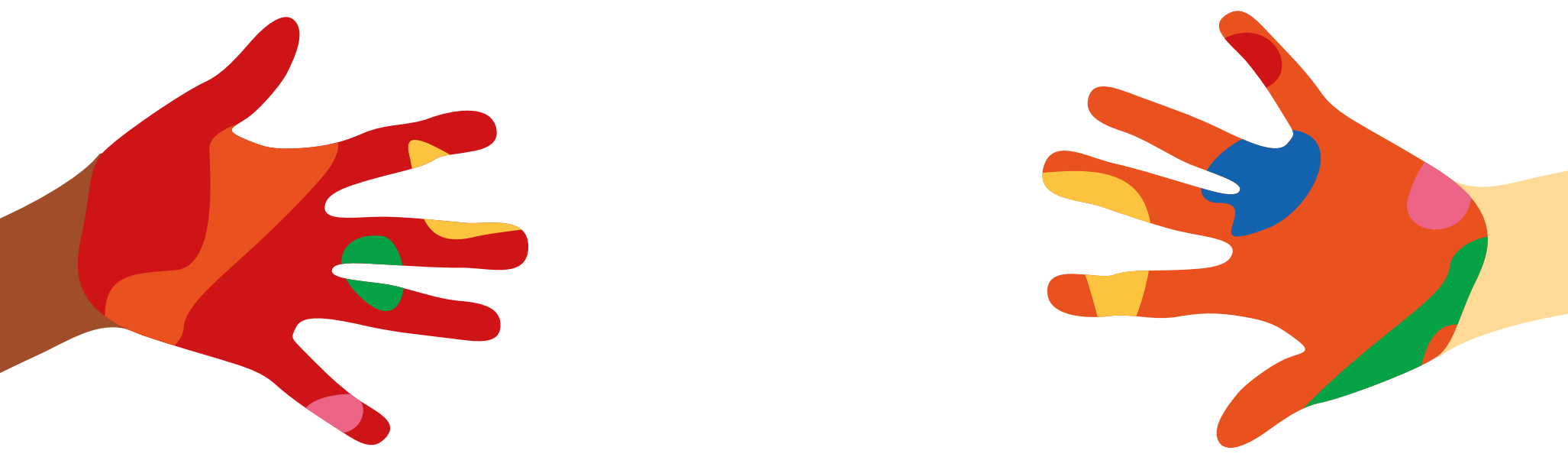


\section{Staff Tool 8 \\ Observing children's play}

Observing children playing can support us to think about how and why children are playing and the things that we can do to respond to their play needs. You can use these questions to draw some conclusions about playing and steps you can take to safeguard or develop opportunities for playing. This form provides a format to use although observations can also be recorded using a voice recorder, reflective diary or other method.

\begin{tabular}{|c|c|}
\hline Date: & \\
\hline When are children playing? & For how long are children playing? \\
\hline Number of children and ages: & Weather: \\
\hline \multicolumn{2}{|c|}{ Who is missing? (i.e. disabled children, older children, girls) } \\
\hline
\end{tabular}


Brief description of site or episode of play:

Space - What sort of spaces are children playing in? What do they offer children in terms of play?

How are the children making use of them? Are they suitable for playing? (see Staff Tool 5)

Resources - What are children playing with? How are they using them? Are there enough things to play with?

Play behaviour - How are children playing? (See Staff Tools 3 and 4)

Challenge and uncertainty - Are children managing risks for themselves? Are there hazards in the environment that it would be better to try to control or mitigate? (see Managers Tool 5)

What are your initial reflections of what's happening? 
Play types - Are you observing a wide or limited range of play types? (See Staff Tool 4)

Other adults - How are they responding to children's play? Are adults helping children to play or stopping them from playing? (See Staff Tools 2 and 3)

Challenge and uncertainty - Are children managing risks for themselves? Are there hazards in the environment that it would be better to try to control or mitigate? (see Managers Tool 5)

What are your initial reflections of what's happening? 


\section{Staff Tool 9 \\ Resourcing play - loose parts}

Resources can be found or provided to facilitate and encourage play. Resources such as sand, water, shells, fabric, buckets, boxes, rope, tyres, bottles, wood and scrap materials of all kinds have come to be known as 'loose parts'. This refers to anything that can be moved around, carried, rolled, lifted, manipulated or combined to create interesting structures and experiences.

Loose parts for play may take on a different value in situations of crisis as they may be useful household or building items. Securely storing these types of materials may be problematic. Children and their families may have few personal possessions, so toys and other materials may be argued over with negative consequences.

However, loose parts provide enormous value for play and efforts should be made to provide them in some way. Staff may need to be resourceful and creative - obtaining nondescript materials that can be used flexibly may work best.

Loose parts give children resources to help them create optimum environments for their play. Because loose parts are not prescriptive they offer many possibilities. Children are often very drawn to making dens and shelters - this is achievable with sticks, fabric and blankets. Scrap cardboard can be used to make signs, shields, costumes and masks. Sticks become fishing rods, spoons in a kitchen or a magic wand.

\section{Loose parts can be natural or synthetic and include:}

- wood

- containers

- shapes

- toys

- stones

- stumps

- sand

- gravel
- fabric

- twigs

- logs

- stones

- flowers

- rope

- balls

- shells and seedpods.

Playing in a space rich with loose parts supports a wide range of development including flexibility, creativity, imagination, resourcefulness, problem solving, self-esteem and spatial awareness. 


\section{Staff Tool 10 Useful and basic play items}

We asked people working in crisis situations if they could take just one thing to support children to play, what would it be?
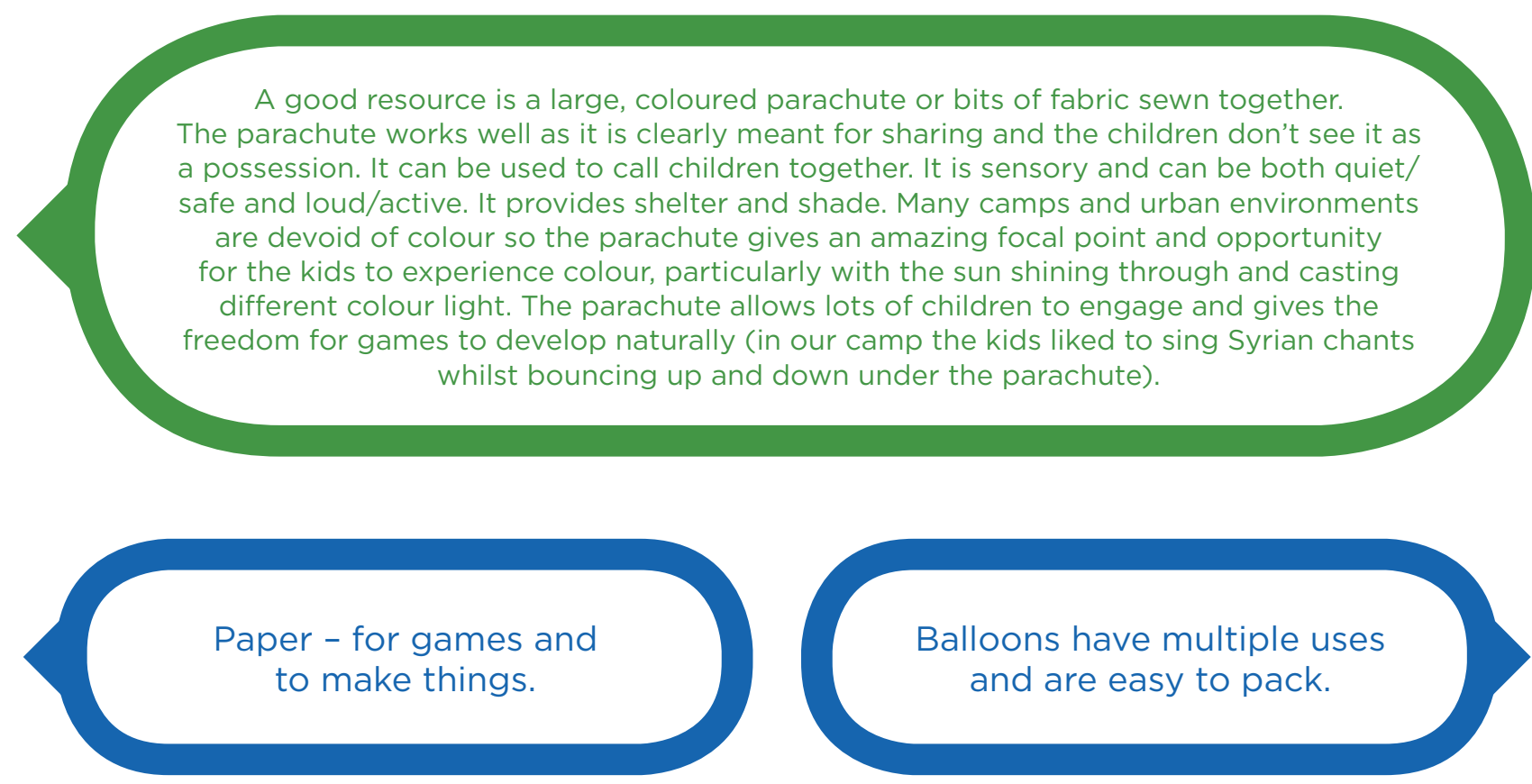

Chalk - to draw with, make games, can transform a space, and can mark a space for play.
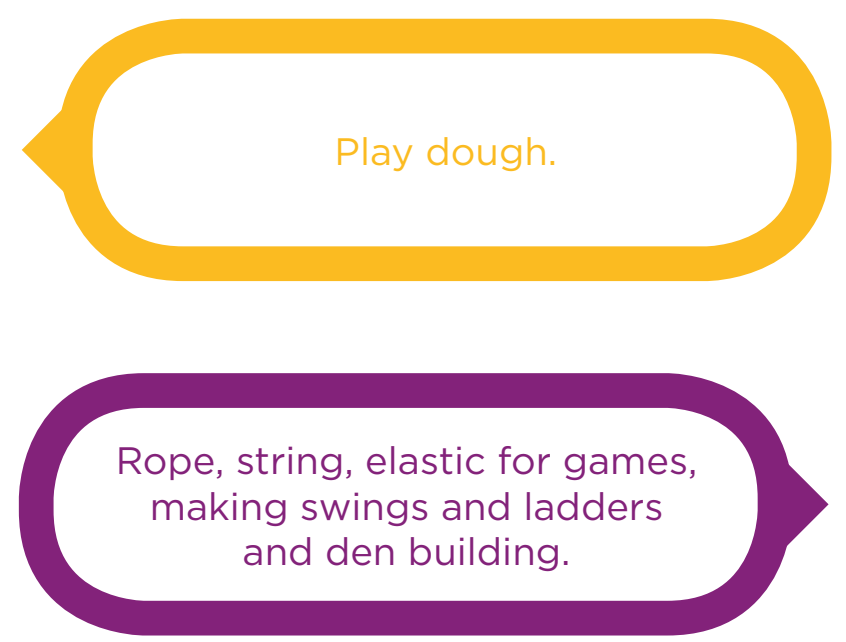

Matches - because making and sitting round fires can be very communal and convivial. Fires can be cooked on, provide warmth and offer place for reflection.
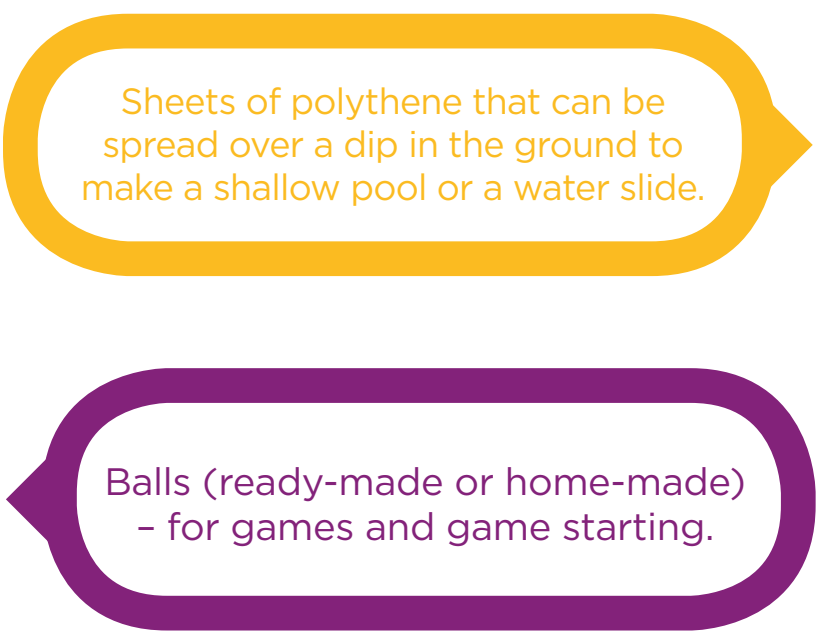


\section{Staff Tool 11 \\ Facilitating the beginning, middle and end of a play session}

Although children will find space and time to play independently, they value the time they spend in a dedicated play session. Every play session will have a beginning, middle and end.

\section{Top tips: Beginnings}

\section{It is important to get the session or programme off to a good start. Here are some ways you can} begin a session effectively.

\section{Find out what you need to know:}

- Number of children

- Ages

- Staff numbers

- Resources available

- Space - where is it? What is it like?

- How long is the session?

- Gain some knowledge of the environment, space and culture

- Respect what is happening already - be diplomatic of what others are trying to achieve

- Understand conditions of trauma and the potential behaviour of children and families experiencing it

- Prepare yourself. Learn from the people already there - is there a routine?
- Learn some basic words in the children's languages such as play, thank you, hello, goodbye, my name is, stop

- Be responsive to the situation. Reflect on your observations. What do the children need and want?

- Work alongside other services such as health and education

- Talk to the other adults to help them understand about the importance of play. Try using childhood memories to make the case

- Start when you say you will - be on time and be ready!

- Stay safe - learn what is the situation from a leader (formal or informal) and talk to the children

- Be clear about what you will provide - stick to this, don't promise what you can't give or do.

\section{Ideas for getting things started}

- Clapping games

- Parachute games

- Rhymes/songs
- Counting games

- Setting out interesting resources. 


\section{What we can do during a staffed play session}

- Observe play - we should be looking out for what children are doing and their interests and preferences. This can tell us a lot about the children we are working with

- Respond to play cues - responding positively when children invite us to play but also recognising what children's play cues tell us about their interests

- Ensure all children feel included - children may be isolated for all sorts of reasons including disability, shyness, trauma, different religions. If possible, we should spend time getting to know the children and finding ways to get them involved

- Ensure that older siblings caring for younger children get to play too we can find ways to engage older children in playing whilst their younger siblings are occupied

- Allow for quiet - play isn't always chaotic and noisy. We should allow time and space for children to be calm and to play quiet games, think or be creative
- Replenish resources - even if we only have limited resources, if possible we should make sure that there are sufficient and suitable resources for play

- Divert children who are bored or whose behaviour is impacting negatively on other children's play

- Provide ideas for games or activities whilst we should not be directing children too much, having a few things that we know work can help to get children engaged

- Communicate with other staff - working as a team requires good communication, even if this is just occasional eye contact to check people are okay

- Allow play to continue without too much adult involvement. This includes talking to other adults so that they understand what we are doing

- Reflect - reflective practice is a constant process. We should think about what we are seeing and experiencing and about how we might improve children's play opportunities. 


\section{Top tips: Endings}

\section{There are many possible endings:}

- End of a session or activity

- End of a placement or period of volunteering (someone leaving)

- End of a project (closing a centre, for example).

Ending a play session can be difficult at times. Some children may not want the session to end; some adults may be coming to an end of their time with the children. Consistency and ritual can ease these difficult processes.

- Offer reassurance that this session has ended but there will be another session - (when and where that will be). It is important to be honest

- Tell the children when the end time is, but also when it will start again

- Use a song or a clapping game to signal the end of a session

- A useful technique used in some settings is to use easily recognised words to signal time to end (for example, in one camp this is called "cleaning time")

- Bring everyone together for a "closing" discussion. We can reflect together on what we gained/enjoyed/understood from playing together; what we would like to do next time; things we want to say

- This is also very beneficial when staff are leaving and enables adults to talk about what they have gained and learnt from their time with the children
- Prepare for ending/leaving. We need to be sensitive and should not leave suddenly as this can cause another layer of trauma

- We need to prepare with the children (and parents who may trust and depend on us) over a period of time. Children can become very attached, very easily and quickly

- Endings can also be in the form of an exhibition, a party, a show, a performance, a celebration (for example, at the end of a project or term of volunteering)

- Try reframing the ending if appropriate. It is good to focus on a new start or a new phase - even if it is a new start alone or without outside help. It may be a time for a new independence and self-reliance. 


\section{Staff Tool 12 \\ Questions to support reflection/reflective practice}

Reflective practice is a term used to describe thinking about our interactions with children, our observations of their play and actively questioning our motives, actions, feelings or concerns.

\section{Reflection can be undertaken in a variety of ways including:}

- Individually - writing in a diary, notes or mind maps, thinking, reading

- Group - team meetings, de-briefing, supervision with managers, peer support

- Actively - reflecting while doing, cleaning, driving, running, acting things out.

It is important that, having actively questioned our practice, we take action and think about what we would change; what we would continue to do in the same way; and how we share our reflections with others. Reflective practice should be used to inform future practice, policies, assessment of risk and challenge and organisational approaches.

In working through a reflection, you may be thinking of a whole play session, an individual episode of play or a series of incidents; and you may want to think it through because the way children or adults dealt with matters went really well, was unusual or puzzling, could have been improved etc. 
These questions are intended to help reflection on the practice

Describe what happened

How did I/we intervene?

What was the response to the intervention?

What was the impact? (for the child or children, colleagues, others, the environment)

What can I/we learn from this?

What are the consequences for my/our future practice? 


\section{Staff Tool 13 Ethical considerations}

In addition to ensuring access to play, there are ethical considerations, to ensuring that assistance offered is positive for children and their families. It is important that we understand our role - if it has not been explained properly, it's important to ask a manager or supervisor.

\section{Be clear of the motives for getting involved}

It is important for anyone thinking about supporting children and families in situations crisis to identify what is their motivation for doing so. Involvement should not be based on boredom, bad relationships at home or work, curiosity, avoidance of issues in one's life, a wish to get media attention. These needs must be addressed in other, more direct ways.

\section{Exercise self-care}

Find ways to self-monitor so that the approach taken makes interventions effective, and not damaging. Keeping journals, having conversations with other volunteers, and Internet or telephone contact with trusted colleagues or family members can provide opportunities to reflect.

\section{Look after health and wellbeing}

Try to get physical exercise, rest, and a healthy diet as part of the daily routine.

\section{Seek necessary skills}

The nature of crisis work may falsely lead professionals to the idea that in an emergency, those available should offer whatever they can. However, in the instance of children's play, staff and volunteers must be open to undertaking training and guidance from mentors to ensure children's needs are met.

\section{Be aware and respectful of cultural issues}

It is likely that cultural diversity will be a factor in most situations of crisis. Where possible, it is important to utilise the skills of other staff or local people to add necessary skill and knowledge to working with an unfamiliar culture.

\section{Receiving and giving gifts}

Great care should be taken in offering gifts. If possible, gifts should be given as resources to be used within activities and programmes, fairly and without discrimination. Gifts should not be given to individual children nor favouritism shown. Gifts should not be given to create photo opportunities. Children may come to expect gifts in exchange for taking part in programmes or activities and gifts can become a form of currency or cause of unnecessary tension.

Families living in situations of crisis may be very grateful for help and support and they may want to show this. They may not have a lot, but there may be a desire to share what they do have with staff. Think through in advance how you will respond and follow organisational or professional guidance if available. 


\section{Safeguarding}

Organisations that support families in crisis situations should have child protection procedures in place, which should be followed to ensure the safety of children.

Many children in situations of crisis can appear eager for adult attention. Children should not be encouraged to make instant attachments with adults.

It is important to help children understand that not all adults who they have contact with always have their best interests at heart. Depending on the context it may be possible to help them recognise which adults have been 'vetted' and have permission to interact with them. If anything goes wrong, children and families should have a way to tell someone.

\section{Avoid showing favouritism}

Children, particularly younger ones, may seek the attention of adults. Do not show the youngest or 'cutest' children or children with the best language skills more attention than others.

\section{Avoid taking or sharing photographs of children without permission}

Tempting as it is to share images and stories on social media etc. ensure you gain consent to use photos, stories or anecdotes. Even, when you have gained this, try not to divulge the identity/ location of those you have been working with in ways, which might make them vulnerable. Bear in mind, photos and personal information may have the potential to put children and families at risk not just in the present, but in the future.

\section{Avoid getting involved in discussion of local or national politics}

The reasons for the situation may well involve politics or humanitarian support. It is not your role to get involved in this, ask questions that lead to it or intrude on the privacy of others.

\section{Do not promise things you can't deliver}

Be realistic and honest with others and yourself. Trust will be built on promises made and delivered.

\section{Prepare for ending/leaving}

Staff leaving or ending programmatic activity suddenly can cause another layer of trauma if not handled appropriately. Providing sensitive preparation, sufficient notice, honesty and straightforward information about what is happening are extremely important.
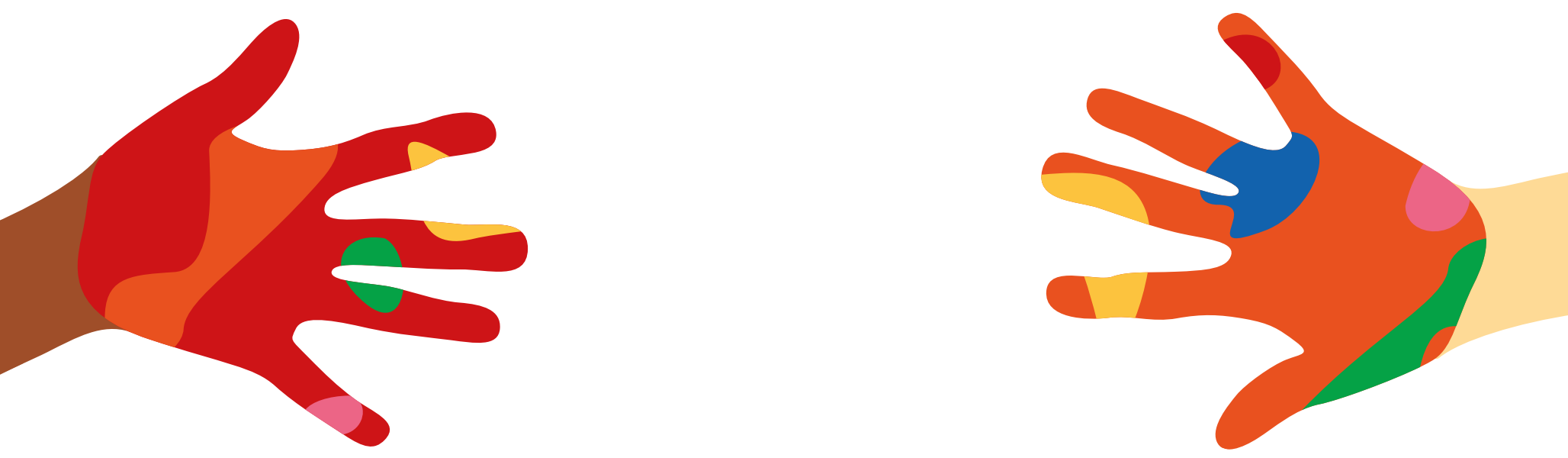


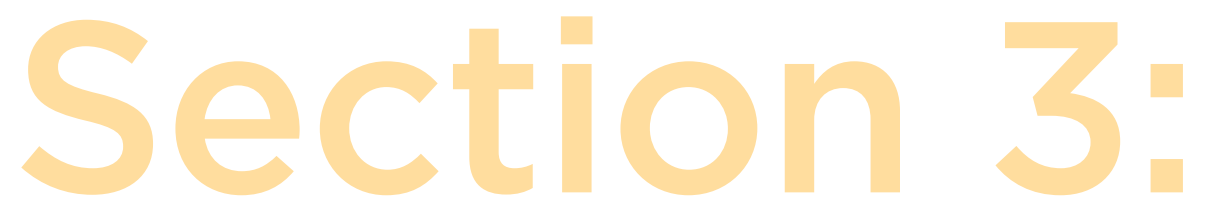

Managers section 


\section{Managers section}

This section provides guidance for those responsible for children's services and managing, supervising and training staff.

\section{Section contents}

Managers Tool 1 Providing support to staff

Managers Tool 2 Providing induction about play

Managers Tool 3 Providing training to support play within programme activities

Managers Tool 4 Identifying and protecting environments for play

Managers Tool 5 Thinking about risk and challenge in play

Managers Tool 6 Spending donations for play

Managers Tool 7 Action planning

Managers Tool 8 Working together

Managers Tool 9 Advocating for play

\section{See also:}

All Tools for Staff. This will help to support staff working with children in situations of crisis.

Policy Maker section: Models of provision. 


\section{Managers Tool 1 \\ Providing support to staff}

We do our jobs well when we feel valued, know what we are meant to be doing, can learn from any mistakes and receive praise when we do things well.

Staff induction, supervision and support and mentoring allow a focus on staff wellbeing, as well as providing professional and personal development.

While supervision deals with the work, support looks after the member of staff.

\section{A good support session or system provides staff with:}

- a safe setting to talk about their feelings about work

- the opportunity to explore professional development

- the opportunity to consider how outside influences are affecting work.

A thorough induction process welcomes new people quickly and efficiently and provides a positive and supportive environment. Many settings use a written induction checklist, record and a timetable to ensure that all areas are covered.

Normally, induction checklists comprise:

- a welcome and introduction by line manager

- an introduction to colleagues, children and families

- a list of staff, their job titles and roles

- a brief history of the organisation

- essential policies/staff handbook

- the completion of necessary personnel paperwork

- a basic health and safety introduction. 


\section{Managers Tool 2 Providing induction about play}

Once essential organisational procedures and policies have been shared and understood by the staff, the induction period can be used to identify learning and skills of staff to understand their role in supporting children's play.

\section{Checklist for a play specific induction}

Taking a child-centred approach provides a useful framework for us to consider how we might use the induction process to reinforce how we provide children with access to the broadest range of environments and play opportunities:

- introducing and reinforcing the issues of children's rights

- principles and values essential for working with children

- health, safety and security

- listening to and communication with children and families

- understanding development and behaviour

- keeping children safe from harm

- a balanced, commonsense approach to managing risk and challenge.

It is the responsibility of the manager or supervisor to ensure that staff understand their role regarding play.

\section{Sample Job/Role Description}

Purpose: To be responsible for the development, delivery and promotion of a programme of play opportunities.

\section{Duties and Responsibilities:}

1. To work as part of a team to develop quality play opportunities with children within the community.

2. To enable and support children to contribute to the development of play projects.

3. To be an advocate for children's right to play under the United Nations Convention on the Rights of the Child.

4. To facilitate children's play through:

- identifying, creating and protecting space and time for children to play

- sourcing loose parts, natural, recycled and flexible materials for children's play

- directly facilitating play where appropriate

- actively including children who would otherwise miss out on play or be excluded from activities

- identifying and acting to remove barriers to play (social or physical)

- bringing a playful and creative approach.
5. To develop links with the community and partner organisations/agencies to help support the development of play opportunities in each identified area.

6. To liaise with the community in order to identify volunteers and peer mentors to support and sustain play in their community.

7. To participate in regular team meetings and training.

8. To participate actively in supporting the principles and practice of equality of opportunity as laid down in the organisation's Equal Opportunities Policy.

9. To work in line with other organisational polices such as child protection and health safety. 


\section{Managers Tool 3 \\ Providing training \\ to support play within \\ programme activities}

A number of participatory training techniques are provided in this section which will help staff think in practical terms about the importance of play and how to facilitate it. This tool should be used alongside the Tools for Staff section and it's recommended that the facilitator/trainer reads those thoroughly in advance and, ideally, has tried them out in real-life situations.

\section{Tips}

- These activities would work well in training sessions for a minimum of five participants and a maximum of about 30

- With a larger group, you might want to have a second facilitator

- The length of time to allocate to the activities will vary depending on the size of the group and the level at which they engage with them

- You can work through the activities over a number of sessions or pick and choose the ones that seem most relevant, however we recommend using them to complement each other and provide a basic shared level of understanding

- Use the various tools referenced here as handout sheets for the participants to take away

- Provide staff with the whole of the Information for everyone and tools in the Staff section

- Make these activities fun in your own way - for example, with a large bell for timed activities, introducing elements of playful competition, preparing colourful visual aids, bringing your own personality to your facilitation style

- Adapt activities as necessary using your knowledge of the cultures and backgrounds of the participants

- Try to adapt the activities to the level of the participants. 


\begin{tabular}{|c|c|c|}
\hline $\begin{array}{l}\text { Activity } \\
\text { Approx. length of time } \\
\text { to allocate } \\
\text { Purpose }\end{array}$ & Description & Resources \\
\hline $\begin{array}{l}\text { Play memories } \\
15 \text { - } 30 \text { minutes } \\
\text { To set the scene. } \\
\text { To engage with experiences } \\
\text { of playing. }\end{array}$ & $\begin{array}{l}\text { All adults have recollections of playing as } \\
\text { children. Ask staff to draw a map of where they } \\
\text { played or a memory of play from when they were } \\
\text { children themselves. } \\
\text { Facilitate the discussion around the key features } \\
\text { of people's play memories. Typical themes } \\
\text { include: freedom, adventure, being away from } \\
\text { adults, taking risks, outdoors and imagination. } \\
\text { Points to consider: what did you find in common } \\
\text { amongst the memories? Are things different } \\
\text { for the children they work with? Do different } \\
\text { generations have different attitudes to playing? }\end{array}$ & $\begin{array}{l}\text { Pencils, coloured pens } \\
\text { or paint, paper }\end{array}$ \\
\hline $\begin{array}{l}\text { Barriers to playing } \\
30 \text { - } 45 \text { minutes } \\
\text { To increase understanding } \\
\text { of the context in which } \\
\text { children play. } \\
\text { To identify ways of finding } \\
\text { solutions. }\end{array}$ & $\begin{array}{l}\text { Ask the group to think of the things that might } \\
\text { stop or get in the way of children playing. Record } \\
\text { the ideas on separate pieces of paper and peg } \\
\text { them up on a 'washing line' or lay on them on } \\
\text { a table. } \\
\text { Once you have 10-15 suggestions, group the } \\
\text { same issues together. Choose one issue and } \\
\text { discuss what could be done to reduce or remove } \\
\text { the barriers. (This could be done in small groups } \\
\text { or one large group.) } \\
\text { Facilitate feedback in the group. } \\
\text { Points to consider: are some children more } \\
\text { affected by the problem than others? What } \\
\text { range of solutions might be useful? Who has the } \\
\text { power or ability to make that change? (e.g. can } \\
\text { the community do this? A staff member? } \\
\text { A government official? Etc.) }\end{array}$ & $\begin{array}{l}\text { Paper, a washing line } \\
\text { or string, clothes pegs }\end{array}$ \\
\hline $\begin{array}{l}\text { The role of adults } \\
30 \text { minutes } \\
\text { To increase understanding } \\
\text { and confidence about } \\
\text { the role of adults in } \\
\text { supporting play. }\end{array}$ & $\begin{array}{l}\text { Using the eight intervention styles in Staff } \\
\text { Tool 2, ask staff in small groups to discuss an } \\
\text { intervention style and what it might mean in } \\
\text { practice. Each group can choose several and } \\
\text { work through them before you stop to ask } \\
\text { for feedback. } \\
\text { Facilitate feedback to the group. } \\
\text { Points to consider: are different intervention } \\
\text { styles suitable at different times? Do some } \\
\text { interventions styles feel more comfortable or } \\
\text { familiar than others? Does anyone in the group } \\
\text { want to ask advice other members of the group? } \\
\text { Are there any occasions when some styles } \\
\text { would not be suitable? }\end{array}$ & $\begin{array}{l}\text { Staff Tool } 2 \text { The role of } \\
\text { adults in supporting play } \\
\text { in situations of crisis }\end{array}$ \\
\hline
\end{tabular}




\begin{tabular}{|c|c|c|}
\hline $\begin{array}{l}\text { Activity } \\
\text { Approx. length of time } \\
\text { to allocate } \\
\text { Purpose }\end{array}$ & Description & Resources \\
\hline $\begin{array}{l}\text { Responding to play cues } \\
15 \text { - } 20 \text { minutes } \\
\text { To energise the group } \\
\text { with a fun activity. } \\
\text { To develop a deeper } \\
\text { understanding of the } \\
\text { impact of play cues } \\
\text { and responses. }\end{array}$ & $\begin{array}{l}\text { Divide the group into two. Ask them to think up } \\
\text { examples of play cues: direct verbal cue, facial } \\
\text { expression or playful action. Ask for a volunteer to } \\
\text { come forward from each group. One of them acts } \\
\text { out a play cue and the other person responds. } \\
\text { Try to make this activity fun and quite quick. Carry on } \\
\text { with as more examples with different people coming } \\
\text { up from each group in turn. } \\
\text { Points to consider: what are the implications of how } \\
\text { responses were made? Did they stop, change or } \\
\text { continue the play? What alternative responses could } \\
\text { have been made? }\end{array}$ & $\begin{array}{l}\text { Staff Tool } 3 \\
\text { Responding } \\
\text { to children's play }\end{array}$ \\
\hline $\begin{array}{l}\text { Understanding loose parts } \\
20 \text { - } 30 \text { minutes } \\
\text { To encourage creative } \\
\text { thinking about loose parts. }\end{array}$ & $\begin{array}{l}\text { As an introduction, talk about some of the things } \\
\text { people mentioned playing with in their play memories } \\
\text { activity or things that they see children playing with. } \\
\text { (Do not emphasise ready-made toys rather things like } \\
\text { a plank of wood made into a bridge over a puddle, } \\
\text { a piece of fabric used for dressing up play.) } \\
\text { Label five sheets of paper, each with one of the } \\
\text { following headings: } \\
\text { Examples of loose parts that would be easily found } \\
\text { in the local environment } \\
\text { Examples of things you can do with loose parts } \\
\text { (build a den, experiment, etc.) } \\
\text { Ideas for sources of loose parts (for example factory } \\
\text { offcuts, builders yard) } \\
\text { - Suggestions for managing loose parts (for example, } \\
\text { checking them for hazards such as nails sticking out } \\
\text { of wood, storage etc.) } \\
\text { shared with each of the participants, or produce } \\
\text { a poster from it. } \\
\text { After five minutes ask the groups to pass the paper } \\
\text { ideas gathered. } \\
\text { whe groups now add as many more ideas as they can } \\
\text { loose parts? }\end{array}$ & $\begin{array}{l}\text { Paper, a washing } \\
\text { line or string, } \\
\text { clothes pegs }\end{array}$ \\
\hline
\end{tabular}




\begin{tabular}{|c|c|c|}
\hline $\begin{array}{l}\text { Activity } \\
\text { Approx. length of time } \\
\text { to allocate } \\
\text { Purpose }\end{array}$ & Description & Resources \\
\hline $\begin{array}{l}\text { Creating environments } \\
\text { for play } \\
40 \text { - } 60 \text { minutes } \\
\text { To share ideas about } \\
\text { features that support play. } \\
\text { To encourage a focus } \\
\text { on creating environments } \\
\text { supportive of play. } \\
\text { To think creatively about } \\
\text { what might be achieved } \\
\text { even in unpromising } \\
\text { environments. }\end{array}$ & 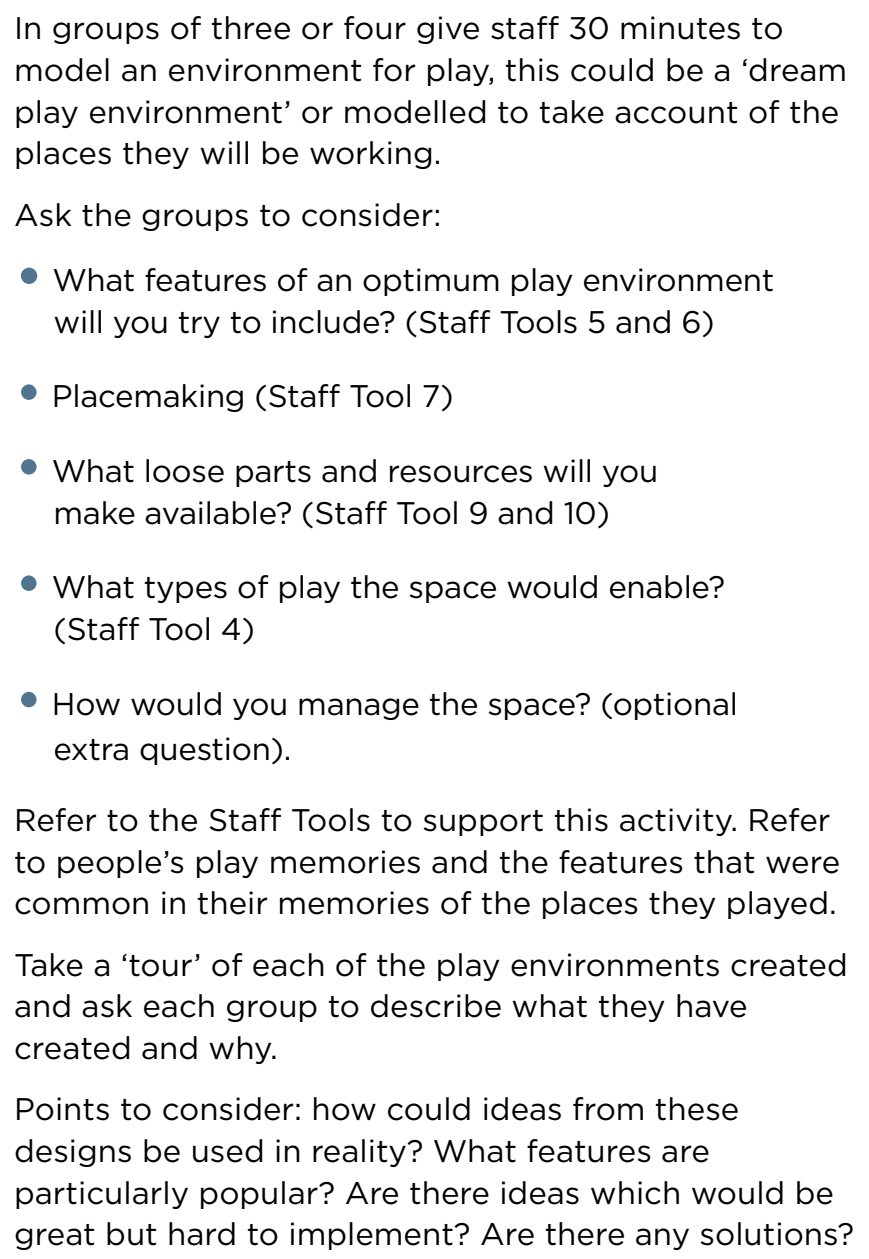 & $\begin{array}{l}\text { Small loose parts, } \\
\text { modelling materials } \\
\text { (e.g. clay, plasticene, } \\
\text { home-made dough) } \\
\text { Staff Tools: } \\
\text { Staff Tool } 4 \\
\text { Play Types } \\
\text { Staff Tool } 5 \text { \& } 6 \\
\text { Play environments } \\
\text { and More features } \\
\text { of play environments } \\
\text { to consider } \\
\text { Staff Tool } 7 \\
\text { Placemaking } \\
\text { Staff Tool } 9 \\
\text { Resourcing play } \\
\text { Staff Tool } 10 \\
\text { Useful and basic } \\
\text { play items }\end{array}$ \\
\hline $\begin{array}{l}\text { Planning activity } \\
30 \text { - } 40 \text { minutes } \\
\text { To establish team } \\
\text { approaches } \\
\text { To enable alternative } \\
\text { suggestions to be } \\
\text { offered and considered. }\end{array}$ & $\begin{array}{l}\text { If you have staff who will all be working together as } \\
\text { part of a team, this is a useful exercise to get them } \\
\text { doing some practical planning. } \\
\text { Using Staff Tools } 11 \text { and 12, ask groups of four or five } \\
\text { to consider the points about beginning, middle and } \\
\text { ending and consider together the following questions: } \\
\text { - How will you plan your sessions to take account } \\
\text { of Staff Tool 11? } \\
\text { bow will you let children know you're going to } \\
\text { be there? } \\
\text { What will adults be doing during the session? } \\
\text { - How will you manage the end of the session? } \\
\text { together to improve practice? } \\
\text { Facilitate a large group discussion based on responses } \\
\text { from the groups on each question addressed. } \\
\text { Points to consider: as a facilitator, be aware of the } \\
\text { make-up of each group and whether everyone } \\
\text { is having an opportunity to put forward ideas } \\
\text { and suggestions. }\end{array}$ & $\begin{array}{l}\text { Paper, pens } \\
\text { Staff Tools: } \\
\text { Staff Tool } 11 \\
\text { Facilitating the } \\
\text { beginning, middle and } \\
\text { end of a play session } \\
\text { Staff Tool } 12 \\
\text { Questions to support } \\
\text { reflection/reflective } \\
\text { practice }\end{array}$ \\
\hline
\end{tabular}




\begin{tabular}{|c|c|c|}
\hline $\begin{array}{l}\text { Activity } \\
\text { Approx. length of time } \\
\text { to allocate } \\
\text { Purpose }\end{array}$ & Description & Resources \\
\hline $\begin{array}{l}\text { Sharing games } \\
\text { This activity could be done } \\
\text { at intervals throughout } \\
\text { a session or series of } \\
\text { sessions. }\end{array}$ & $\begin{array}{l}\text { We all have memories of games that we have played } \\
\text { when we were young or from our experience of } \\
\text { working with children. Adding a 'games share' to the } \\
\text { training session gives staff a chance to share games } \\
\text { that can be used to start a session or to provide } \\
\text { a different focus when needed. Think about: }\end{array}$ & \\
\hline $\begin{array}{l}\text { To generate games that } \\
\text { can be used by everyone } \\
\text { in their work. }\end{array}$ & $\begin{array}{l}\text { Clapping games } \\
\text { Skipping rhymes }\end{array}$ & \\
\hline To have fun together. & $\begin{array}{l}\text { Songs (counting songs, songs that reflect } \\
\text { different cultures and backgrounds) }\end{array}$ & \\
\hline $\begin{array}{l}\text { To share games and } \\
\text { songs from different } \\
\text { cultural contexts. }\end{array}$ & $\begin{array}{l}\text { Large group games (tag, ball games, } \\
\text { running games). }\end{array}$ & \\
\hline
\end{tabular}
can be used by everyone 


\section{Managers Tool 4 \\ Identifying and protecting environments for play}

Identifying a place for playing can be challenging, particularly in situations of crisis. Nonetheless, good spaces to play within a community show that playing is important. They create a hub for a community, offering opportunities for adults and young people to become involved and socialise together.

There are a number of models of provision within The Policy Makers section of this toolkit. When engaging with policy makers to identify the best model for play, it is useful to consider a number of principles when thinking about environments.

\section{Wherever possible environments for play should:}

- Make use of natural elements if possible

- Provide a wide range of play experiences

- Be inclusive and accessible to both disabled and non-disabled children

- Allow children of different ages to play together, but also allow specific age groups to have time together (e.g. very young children, teenagers)

\section{Things to consider in the short term:}

- Consider the location for the play environment very careful - will children feel safe walking there and back?

- What toilet and washing facilities are/can be made available?

- Is the space used for anything else and how will that impact on the children?

- Organise some introductory play sessions to help children, parents and other colleagues understand what you will be offering

- Advertise and promote what you will be doing
- Provide opportunities for risk and challenge

- Be looked after and maintained

- Respect children's choices about where and how they play

- Allow people to connect with other people and enhance opportunities for socialising.

- Be as visible as possible. Try to make sure other professionals, adults, parents and children can see what is happening

- Reflect with colleagues so that successes can be celebrated, challenges can be discussed and solutions to these identified

- Make sure there is an understanding of the community - find out as much as possible about the characteristics, culture, and demographics of the community to be served. 


\section{For the long term}

- Environments for play have an important role in long-term community rebuilding efforts, including the creation of childfriendly communities

- Advocate for space for play to be built-in to the plans for permanent or semi-permanent dwelling areas. These do not need to be equipped play areas but safe places for children to within walkable distance of their homes and schools

- Schools have the potential to offer safe, regular play opportunities for children space and time for play is essential as well as training for adults
- Identify local services to work with to help integrate the parents and their children into the local community

- Make links with services children will access on an ongoing basis. For instance, children may attend health services, formal education or schools. Work with education and other agencies to help them to ensure a playful experience for children.

See:

Section 1: The features of an optimum environment for play

Staff Tool 5 Play environments

Staff Tool 6 More features of environments for play to consider

Staff Tool 7 Placemaking 


\section{Managers Tool 5 Thinking about risk and challenge in play}

Risk normally means the possibility of something bad happening like a child getting hurt but some manageable risk is good for children. Children actively seek out challenge and adventure when they play, sometimes with elements of genuinely risky play within it. For example, when a child is balancing along a wall they could fall and be hurt but they are also practising balancing, are active, feeling proud of themselves and having fun.

We should approach managing risk and challenge in play by looking at the balance of risk with the benefits to the children in terms of physical and emotional wellbeing and development. In adventurous, challenging and risky play children may be gaining benefits such as:

- Physical skills

- Ability to assess risks for themselves

- Testing their own abilities

- Mastery

- Building confidence
- Building resilience and problem solving skills

- Experiencing a range of emotions such as thrills, exhilaration, fun, fear, pride, comradery

- Care for others, keeping them safe and awareness of own safety.

There is a difference between the everyday behaviour of children seeking out challenges in their play and children being forced, due to their situation, to play in hazardous, harmful conditions.

In situations of crisis, where children may be playing in hazardous environments, having access to play opportunities supported by adults can help to keep children safe.

Many children play in highly hazardous environments daily (for example, near unsafe buildings, deep water, open sewers, busy roads or train tracks). These require long term solutions. Children still need to play in the meantime and will use the spaces available to them, often very creatively. Although the places children choose to play may not seem ideal, it is important to respect why they have made these choices in the circumstances they are in.

\section{Creating spaces as alternatives for children in the short or medium term can:}

- give them the opportunity to experience types of play they might not be able to access otherwise (for example play that is more reflective, more inclusive, can go on for longer without interruption, which brings in a wider range of resources or perspectives, which feels safer)

- help them to develop a wider range of skills and abilities

- help them to develop their resilience - coping strategies, problem solving, ability to manage difficult experiences (and perhaps replace unhelpful strategies with more positive ones). 
Children also take emotional risks when they play. These might include:

- Playing in ways not deemed typical for their gender

- Playing out traumatic or stressful events

- Appearing foolish or silly

- Trying to establish friendships despite the risk of rejection or loss

- Openly disagreeing with the dominant view of other children.

When children have experienced highly traumatic events, adults may feel reluctant to support children playing in a way that seems to cause further emotional upset to them or others. There can be a temptation to try to distract children or to worry if their play seems to be serious rather than fun.

However, it is important to remember the restorative and therapeutic qualities of play. Children may need to play through their experiences as a way of coming to terms with them and transforming them into something they can better deal with or understand. Sometimes this process can be difficult for adults to witness (for example if a child recreates their home being washed away in a flood, or acts out violence they have seen by punching a toy).

It may be necessary for adults to simply remain a calm presence while ensuring the child does not come to harm through the process or cause harm to others. Within a play context adults might actively look for a way for children to take out their frustrations in a safe way, for example:

- Smashing up a cardboard box

- Building with sand and stamping it back down again

- Building towers of wooden blocks and knocking them over

- Playing a very physically active game

- Providing modelling clay for children to recreate and work through experiences that have impacted on them

- Making drawings or writing stories and then throwing them onto a fire.

Adults will need to agree, for the situation they are in, what behaviours are acceptable and unacceptable. Hurting other people, damaging property or bullying are unacceptable and may escalate with severe consequences leading to further conflict or antagonism in the community.

A few children have very challenging behaviour. There will always be a reason for this: it may have been learnt from other adults; they may have been consistently rejected or hurt; they may be exhibiting any one of a range of disorders; they may have been bullied or abused; they may be 'playing out' their life experiences in order to make sense of them. They still deserve and need understanding and respect, and sometimes one-to-one or specialist help if available. 


\section{Finding a balance}

The questions below are intended to help us think about risks and benefits so we can concentrate on the most positive impact on children's play in situations of crisis. The list is not exhaustive.

\section{Risks}

- Are there hazards in the environment which children cannot be expected to manage themselves?

- Can we do anything to change the environment or reduce the level harm from the hazard?

- Are children creating risky situations themselves? (for example, jumping from heights)

- Are they aware of the possible harm and managing the risks for themselves? (for example, have they created a soft landing or gradually built up to the height they are now jumping from)

- Are children taking emotional risks that are unsettling to us as adults?

- Are there things that we can do to reduce serious risks of harm whilst still enabling children to experience challenge?

- Can we provide secure spaces for children to play more safely?

- Can we provide different materials for children to play with to reduce serious risks of harm?

- Can we do things to enable more varied ways of playing?

\section{Benefits}

- What developmental benefits are children gaining from the way they are playing?

- What physical benefits are children gaining from the way they are playing? (for example, physical activity, co-ordination, body awareness, physical confidence)

- What emotional benefits are children gaining from the way they are playing? (for example, self-awareness, confidence, sense of achievement, socialisation)

- Is the children's play helping them to understand their environment or situation in a positive way?

- Are children enjoying themselves?

- Are children making friends?

\section{Supporting children's behaviour}

- Remain calm

- Provide resources for expressing feelings safely

- Remember behaviour is often a way of children telling us how they feel

- If behaviour looks as if it will become dangerous, try diffusing the situation with another activity or resource

- Ask a child/children to come back at a specific time to discuss what they need to do to be allowed to join in again

- As a last resort ask a child to leave

- Following the incident, reflect on it and speak with colleagues to identify solutions

- Whatever the behaviour, try to avoid permanently excluding children from play sessions

- Avoid shouting at children

- Do not hit children or use other punitive methods.

\section{Using rules to help manage risk and benefit in play}

Rules are fine to help so long as they are:

- necessary

- for children's benefit

- agreed with and understood by children

- few in number

- very clear

- also applied to adults

- revisited often. 


\section{Managers Tool 6 for play}

From time to time, we may be asked to spend money that has been donated, secured through fundraising or allocated from a large organisation or government department. Here are some suggestions of useful purchases.

\section{Shopping list for play}

- Rucksacks/back packs for staff to carry play resources

- Small carts for staff or children to transport play resources and as a play item

- Storage crates or bags

- Water bottles and carriers

- Balls of various sizes

- First aid kits

- A portable tent or stretch sail shade

- Waterproof clothing (staff/children)

- Play parachute (available from specialist suppliers)

- An 'earth ball' (available from specialist suppliers)

- Selection of fabric pieces

- Tarpaulins, large sheets of plastic, rugs

- Ropes

- Matches

- Towels

- Chalk

- Art and craft materials - paper, crayons, paint, sequins, glue, paint brushes

- Air-drying clay

- Ingredients for play dough - simple dough made from flour, salt and water
- Buckets, bowls, baskets of various sizes

- Hand tools for building, such as hammers, nails, poles

- Extra materials to help with building and making - rope, duct tape, pegs, string, sticks

- Sand and sand toys, sieves, buckets, shovels

- Balloons

- Face paints and brushes

- Building blocks

- Checkers/draughts

- Simple picture card games

- Cricket bats, hoops, bean bags

- Play boxes - full of low cost items (such as pencils, crayons, small loose parts, paper, small figurines)

- Resources for small world play large shallow trays, mini figures (people, animals, vehicles)

- Play training for staff and volunteers

- Stationery: stapler, erasers, hole punch, sticky tape

- Printing - International Play Association article 31 posters and other promotional items

- T-shirts for staff/volunteers. 


\section{Managers Tool 7 \\ Action planning}

Work with staff and volunteers to gather information using observation and reflection questions.
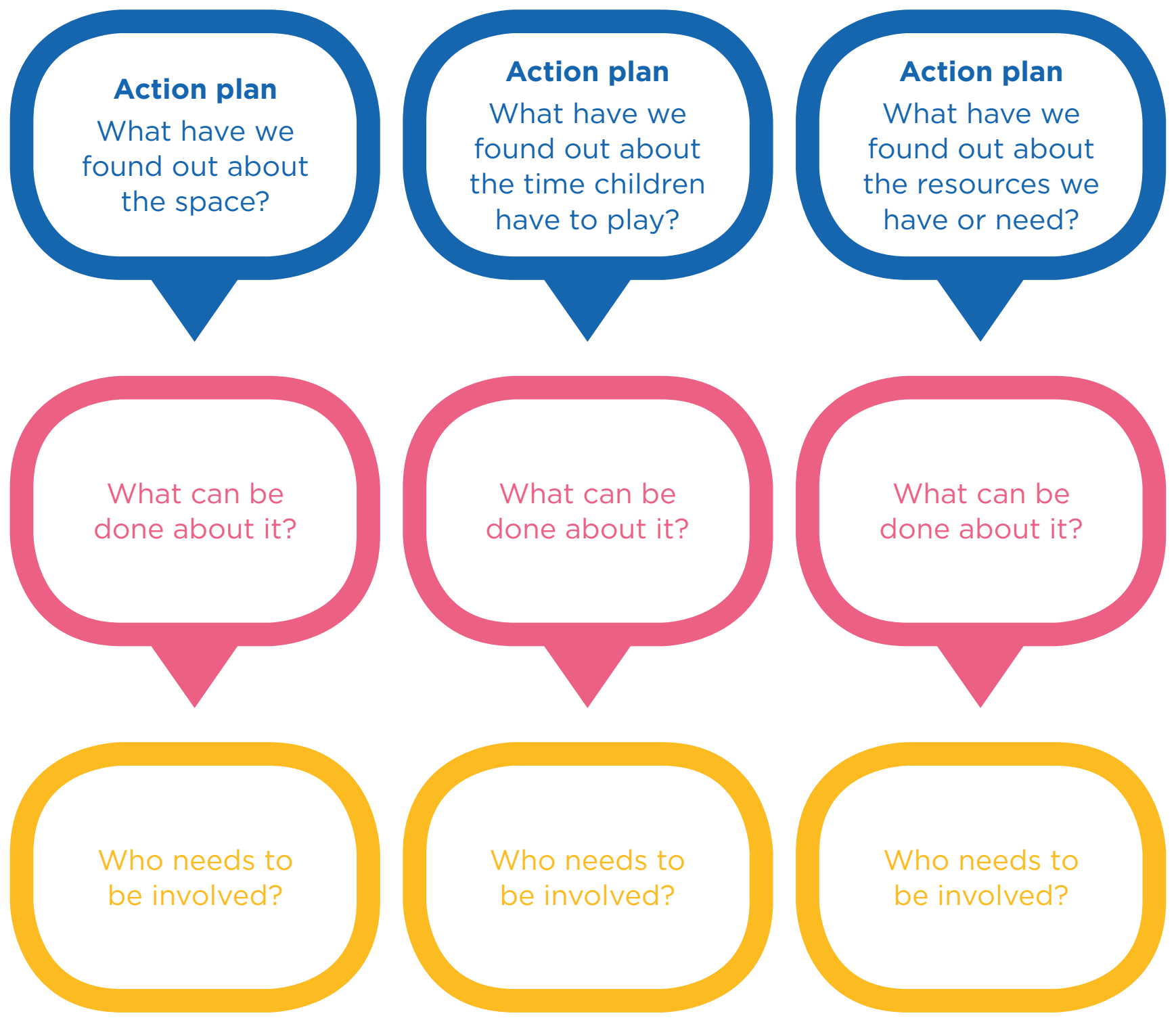


\section{Managers Tool 8 \\ Working together}

It is useful for a number of individuals and groups to come together to plan the arrangements for providing opportunities for children in situations of crisis,

Holding a community event may be a good way to help parents and others to understand what the plans are and how they can help. Here, ideas can be shared and the play opportunities that will be available for children and young people for their own free play can be discussed.

This may also provide a good opportunity to promote the importance of play to parents and the wider community and allay any fears they may have.

Look at the skills in the group and wider community.

\begin{tabular}{l|l}
\hline Skills needed & Who has the skill \\
\hline Leadership & \\
\hline Supervising workers & \\
\hline Team building & \\
\hline Managing conflict & \\
\hline Time management & \\
\hline Managing change & \\
\hline Project management & \\
\hline Monitoring work & \\
\hline Evaluating work & \\
\hline Specialist play knowledge & \\
\hline Specialist childcare knowledge & \\
\hline Publicity skills & \\
\hline Risk management/assessing & \\
\hline Planning and design & \\
\hline Luilding & \\
\hline Maintenance and repair & \\
\hline
\end{tabular}




\section{Managers Tool 9 \\ Advocating for play}

One of the most important roles for adults wishing to support playing children is an advocacy role. This will involve making the case for play through awareness raising. It will often involve proposing solutions to a range of stakeholders such as policy and decision makers, parents, the media and affected communities.

To support the work of play advocates, the International Play Association (IPA) has a worldwide campaign to build awareness and understanding of the importance of play in the life of all children. It aims to break down the increasing challenges in children's living conditions that have a negative impact on children's space and time for play.

To support the campaign, IPA has produced a vibrant short film:

http://ipaworld.org/ipa-video-this-is-me-the-childs-right-to-play and child friendly. and child friendly resources to promote article 31 of the Convention on the Rights of the Child. They help children and adults understand the key messages of General comment No. 17. The resources can be used with stakeholders and key decision makers and stakeholders across a range of intervention levels:

- National programme

- Local programme

- Community level

- Project level

- Practice level (e.g. responses made directly with children, groups of children and families).

The resources include a postcard, a small poster and a large poster with the key messages. All the resources are available to download and share.

\section{http://ipaworld.org/resources/for-children/colouring-pages}

The colour logo on this page can be used on printed matter that staff use. Members of IPA have used the logo on badges and T-shirts to identify staff and volunteers. Others have created flags to mark an area for play.

The monochrome logo can be used with children and their parents to begin to talk about the right to play. Colouring in activities can prove therapeutic and using this with parents offers the opportunity to begin to speak about play in a non-threatening way.

The A3 and A4 posters

\section{http://ipaworld.org/resources/} for-children/fun-things can be used to promote the importance of play with adult decision makers. It provides easily accessible information about the

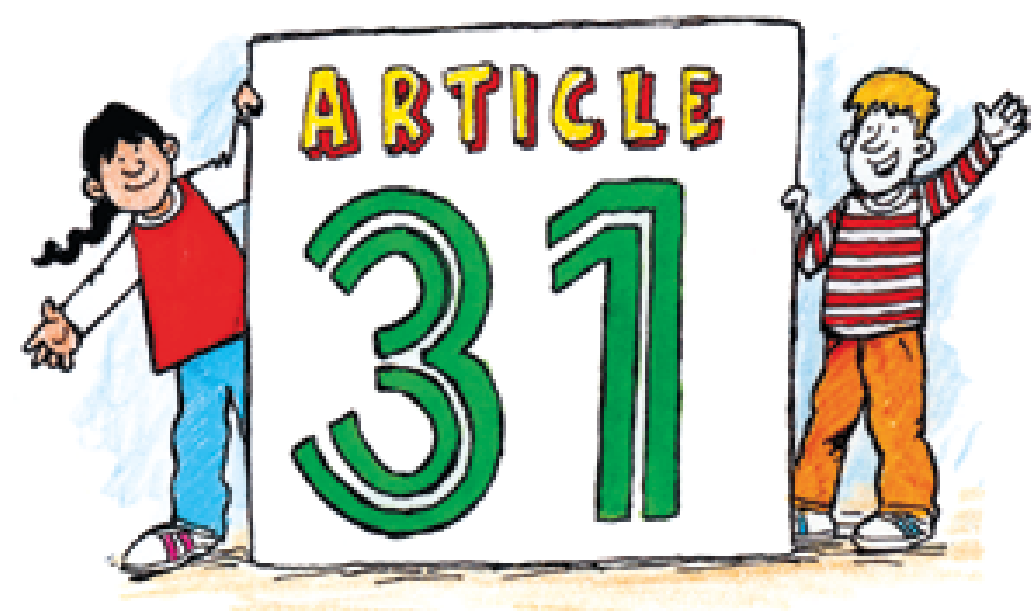
Convention on the Rights of the Child and article 31 rights. 
Section 4: policy

Makers

section 


\section{Section 4 \\ Policy Makers section}

This section provides guidance for Non-Governmental Organisations (NGOs), UN agencies, local, municipal and national governments. It presents a range of ways that services can be developed for children in situations of crisis. It supports policy makers to meet obligations under the Convention on the Rights of the Child. It is intended to enhance and support implementation plans so that all children have the chance of sufficient time and space to exercise their article 31 rights.

\section{Section contents}

Policy Makers Tool 1 Play policy

Policy Makers Tool 2 Models of provision

Policy Makers Tool 3 Working together to provide for the right to play in situations of crisis

Policy Makers Tool 4 Self-assessment tool: providing an optimum environment for play

\section{See:}

Section 1: Understanding the features of an optimum environment for play

Information for Everyone
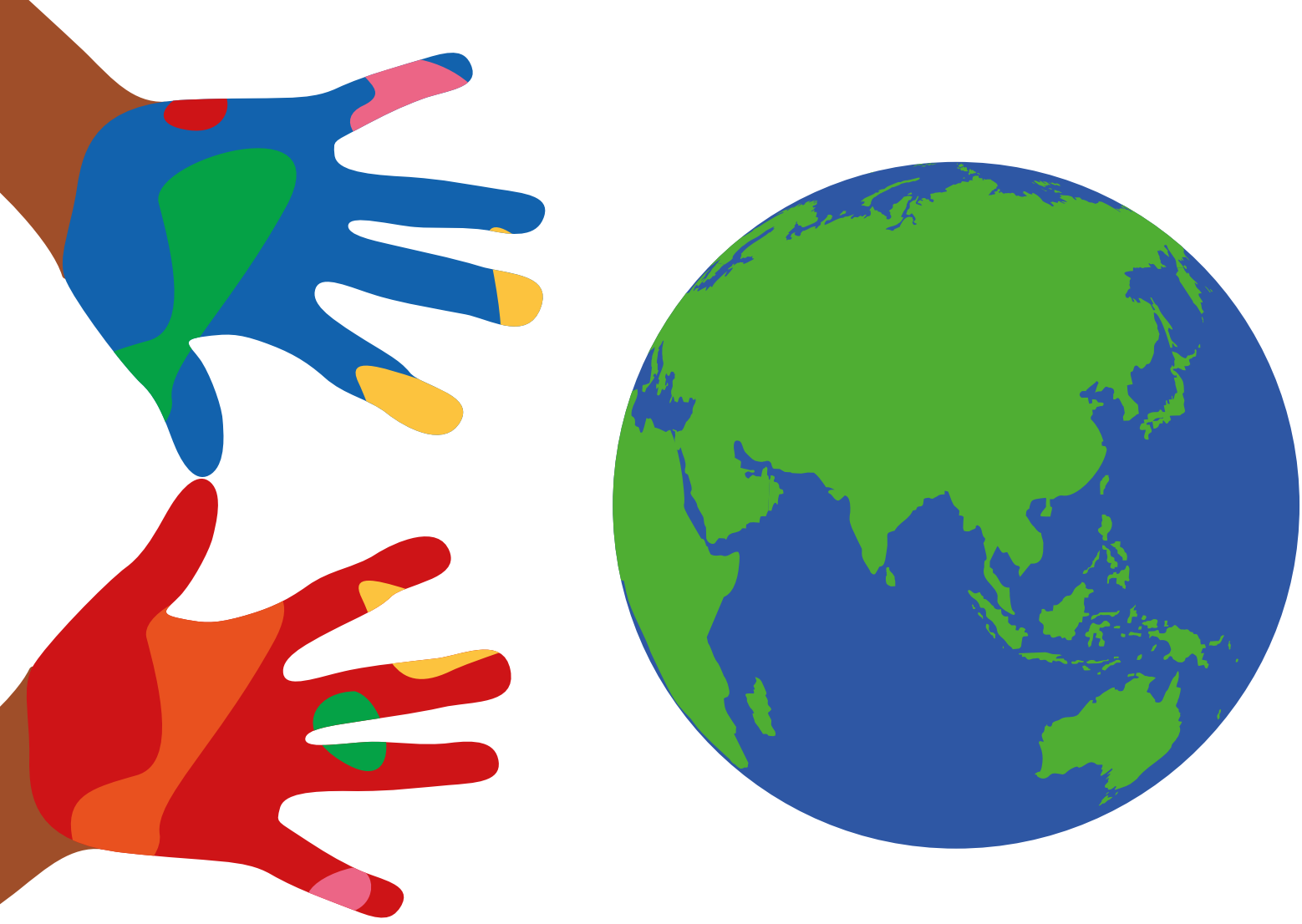


\section{Policy Maker Tool 1 Play Policy}

Developing and adopting a play policy can make a significant contribution to providing sufficient play opportunities for children. A play policy states the value that the organisation places on children's play. It sets out how the organisation will support children's play opportunities. The policy can be shared with the children, staff and parents and be included in the information about the wider support service offered.

\section{Play Policy Statement Template}

[This setting/organisation] recognises the importance of all the children having time and good spaces to play every day.

To children, playing is one of the most important aspects of their lives. Playing contributes to children's health, wellbeing and happiness as well as to their learning and their ability to learn. Most importantly playing contributes to children's ability to thrive and survive.

We believe that we can make a positive contribution to children's lives by valuing their wish and need to play and providing for a broad range of play opportunities as part of the services we provide to children and families.

We believe that adults' attitude towards, and understanding of, children's play behaviour has a significant effect on the quality of the play opportunities offered.

[This setting/organisation] commits to working towards children having sufficient every day play opportunities as described in the UN Convention on the Right of the Child.

\section{In the short-term we commit to:}

\section{In the medium-term we commit to:}

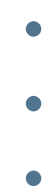

In long-term planning, we commit to:

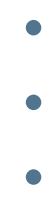




\section{Providing indoor spaces for children to play}

Well-designed indoor spaces for playing should be planned so that they can be used flexibly and offer an appropriate range of opportunities for children of different ages, abilities, circumstances and interests. The provision of community play facilities supports community engagement and acts as a springboard for other services and community involvement.

Being able to access well designed and resourced play spaces and staffed play provision has a huge benefit for the children, parents and the community.

\section{Key features of well-designed indoor space for play:}

- Provides rich experiences - children can explore and experiment through direct experience

- Provides a sense of belonging - children can be close to people they know, have familiar and comfortable objects, and be in a setting that has a personal history for them

- Contains resources that are appropriate, well maintained and accessible for all children

- Planned so that they can be used flexibly and a varied range of activities is provided

- Provides shelter from the weather and a contained, safe and reliable place to play.

\section{Case study}

The children have limited access to indoor spaces to play; they live in small tent-sized huts and have very few, if any, personal belongings. The camp itself is an unsafe living environment with many hazards; it is bordered by a motorway on one side and a train track on the other, with a steep edged deep drainage ditch and several drainage pipes. The conditions are cold and damp.

It was evident that residents would benefit from a dedicated children's centre. There were delays in planning permission, possibly due to pressure from the government and the type of building, leading to building work being halted for several weeks. For many months, there was one small space (tent/building) for all the children on the camp - over-crowding and wide age-range made it dangerous and difficult to provide age appropriate activities. It was impossible to separate age groups for the first few months, as there was no other child-friendly indoor space to protect from cold weather.

When planning permission was granted with the good will of local authorities, support from charities helped raise funds and to build a centre. Using a temporary structure that requires no planning permission may meet the play needs in the first instance. A more permanent building could come later.

(Long term manager, European refugee camp) 


\section{Model B \\ Outreach play provision}

Outreach play provision involves a small team of staff visiting parts of the community, on a regular planned basis - for example, once or twice a week for a couple of hours. They come with ideas and equipment, and work to help children find places to play in their local area, and to reassure parents that it is safe for children to take part in play sessions. These sessions help to increase child and parental engagement and will provide support for families to integrate.

Playworkers and other staff offer a range of play opportunities that children may not have access to otherwise, such as creative activities, messy activities, sensory activities and socialising.

\section{Case study}

After the East Japan Great Earthquake in 2011, Japan Adventure Playground Association contacted Shanty International Volunteer Association, which was delivering emergent programmes in the disaster, and offered to provide a playground for children in the tsunami-hit areas.

The land, an unused allotment, was provided by a landowner. Adventure playworkers and student volunteers from other parts of Japan came to help at the playground one after another.

With a help of the community leader and his wife, a playground was opened in the unused allotment. Playworkers built the playground with visiting children and neighbouring adults using available materials. Logs were collected from the heaps of tsunami rubble. Children carried bamboo cut from the adjacent groves. The signboards were drawn and built by children. Neighbours taught playworkers how to use heavy machinery.

A fireplace was built and tools for building were made available. Play equipment such as a slide, a swing, a shed, and a water pool were built and an adjacent pond was popular for catching mud crayfish.

Community events were held in the playground inviting neighbouring adults to raise community spirit. To increase understanding from adults, the core playworkers visited schools and gatherings in the community.

A call for donations was repeated nationwide for the playgrounds' sustainability. The playground welcomed many study visits. The management of the playground was passed to a local community group in 2012. Since then, a community Non Governmental Organisation runs the playground. (Playworker, established play NGO)
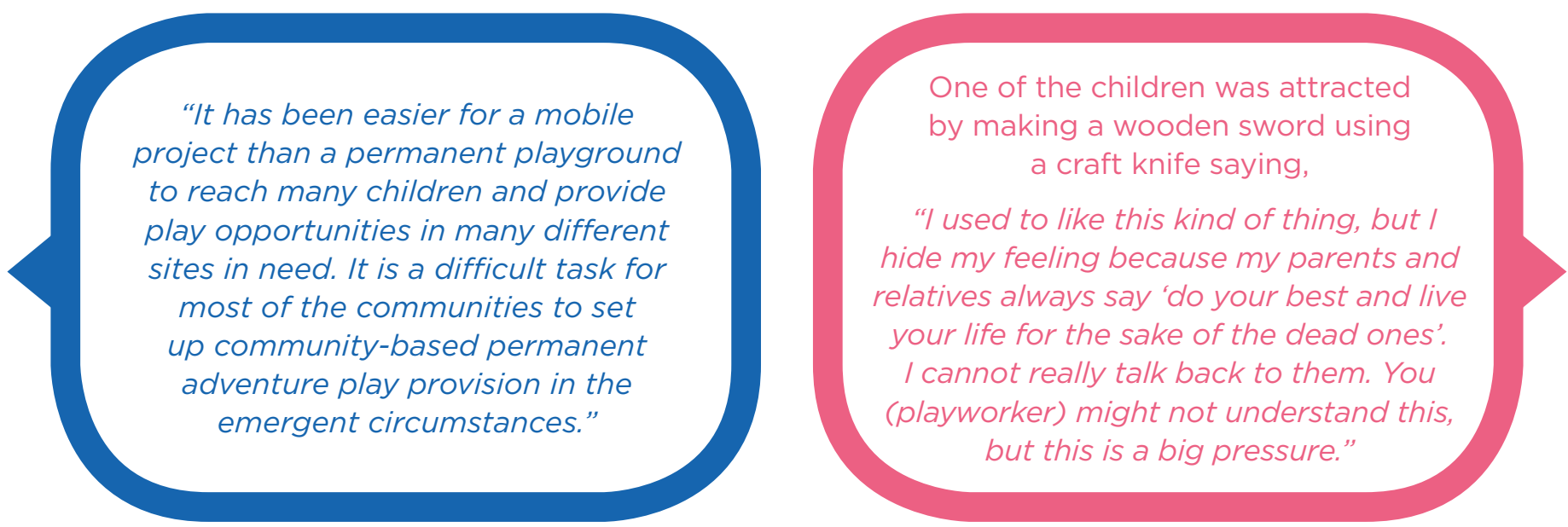


\section{Play equipment and outdoor play spaces}

Good spaces to play show the people in the community that playing is important. They can be a hub and create a community focus, offering opportunities for adults and young people to become involved and socialise together. Children and families value quality play spaces, the relationships they make through them and the way they help them feel a sense of belonging. Play equipment can offer shared experiences and some equipment such as shelters provides space for socializing.

To make the most of a play space, children need to be able to adapt and shape it to meet their play needs and it needs to change over time and provide new opportunities for play. The addition of loose fill surfaces such as sand or bark, the inclusion of water, and trees and bushes will provide a supply of play materials that change with the seasons, which children will use in a variety of ingenious ways.

\section{Key features of outdoor play spaces and things to consider:}

- Spaces should be designed with the needs and characteristics of the local community in mind in identifying location and likely range of use and users

- Spaces should reflect distinct local characteristics in terms of the design, materials and features included

- The existing natural features should be respected and where possible different levels, existing trees and natural puddles should be integrated

- The site as a whole and location is as important as individual play features in creating a successful play space
- Spaces include play materials and play features that are non-prescriptive and therefore encourage imagination, suggesting many ways of being played on or with

- Spaces do not rely mainly on manufactured play equipment for the play opportunities offered. Spaces use manufactured equipment to enhance what is on offer

- The design of the space ensures that when play equipment is used, it is integrated with and complements other site features

- The space incorporates opportunities for children to encounter or create challenge and adventure.

\section{Case study}

The children, having a lack of toys or man-made play materials use natural resources instead. A group of girls aged five to eleven pick pine needles from a tree. This has been popular recently so the easily accessible branches are bare. The girls decide they need to go higher. They begin by trying to lift each other up, this doesn't work so they get a chair and stand on it, and this also fails. They then work together to move a school desk under the tree and then all climb on top of the desk and one by one reach up but with no success.

Undeterred they sit on the table and discuss. It seems they come up with a plan because after a couple of minutes they move the table to the trunk of the tree. The biggest and the smallest of the girls are then selected. The biggest stands on the table and lifts the little one into the branches. The little one slides along the branch and then proceeds to tear off handfuls of pine needles and throw them down, this receives a cheer and clapping. The little one is helped down from the tree. This interlude resulted in beautiful chains and pine needle sculptures, given as presents to volunteers. (Medium term volunteer, small voluntary-run refugee camp). 


\section{Supporting community self-build play spaces}

Community-built permanent or semi-permanent play spaces can be developed, built and maintained by local people to meet the needs of their community as a significant longer-term effort to create space for play.

Developing a play space using manufactured equipment and surfacing can be an expensive process but often, with appropriate guidance, there are a range of skills that already exist in communities that can be employed to make quality play spaces and to make money and resources go further. At the same time, working together on a play space can nurture a sense of community cohesion and ownership.

\section{Key features of successful community build projects:}

- Support community cohesion

- Utilise local skills and resources
- Respond to local need

- Support skill sharing and skill building.

\section{Case study}

A team of professional volunteers from the UK has worked closely for eight years with residents and children of Halabja, Iraq to exchange experiences, ideas and practices in how to best serve the child's right to play. At the informal request of children and parents, the Halabja Community Play Project took shape between residents and a volunteer group from the UK to establish an adventure playground. Working closely with the town's residents and municipality, research with the children and families was undertaken. An understanding of what the children needed was gained through consulting and observing how children played and noting what types of play were absent. We started on the site by introducing playing all sorts of games and play materials, from pencils to play-parachutes. The site was consistently invaded by cows and it was the children who came up with the idea of a wall.

Over time, a trusting relationship between adults and children and between residents and visitors was built. This enabled the project to understand the needs of the community as well as the children. At every chance the children had to be involved or do something practical so they became the experts in each task. An inclusive work programme allowed the children to determine and physically work on the design, build and the running of the playground.

Having the adventure playground open daily and staffed by enthusiastic and local people who understand the culture and importance of play best serves the needs of the children in gaining support, time and the space to play. (Manager, long-term community project)
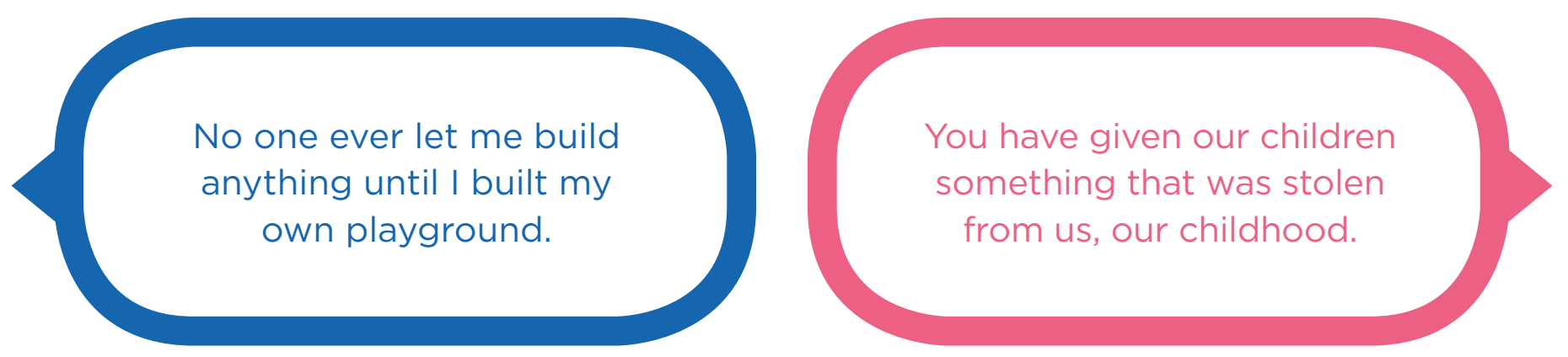


\section{Encouraging integration into local play provision}

Sometimes, it is possible to work with local services towards helping families integrate with the local community or community services.

It is common for families experiencing situations of crisis to feel disengaged from the local community. The children can often feel isolated and discriminated against.

When play projects have successfully supported integration, they have started by working on sites, taking the children out on organised trips to local attractions or by organising events for parents and younger children.

This approach helps projects to gain the trust and respect of parents and supports them to suggest that the children and young people may benefit from the use of local community-based facilities. Successful integration projects can help to give children and young people a voice.

\section{Play services can:}

- Provide children with the opportunity to discuss issues that are important to them

- Help children understand their rights

- Support children and families to gain the confidence and skills to engage with other professionals
- Help children to take skills and learning back to the others

- Help children to understand the importance of rules and boundaries, while understanding their own rights.

\section{Key features of successful integration or things to consider:}

- Workers have a strong understanding of the culture and cultures of the community

- Workers contact other service providers already known on site to be introduced to community members

- Workers are clear about the nature of the provision and how parents can support it to help allay parental concerns
- Workers consider arranging visits to provision for parents prior to organising sessions for children

- Any issues regarding transport are identified and addressed before the process of integration starts

- Workers understand that integration takes time and need to be aware that this may be challenging for all children and families.

\section{Case study}

The play centre attracts children aged 5-14 from the local area and also children from who are refugees and asylum seekers. We began running play sessions for asylum seeker children a few times a week in the hostel that was temporarily housing children and their families. However, the hostel was unsuitable for children's play. There were safeguarding issues and not enough room to support the play needs of a wide range of children from different backgrounds. Nevertheless, the play sessions allowed us to gain the trust of the parents and we suggested that the children started to use the facilities in the nearby play centre.

We designed a bespoke project to help break down barriers. We facilitated a 'walking bus' where we chaperoned children and their parents to the play centre for specialist sessions. Whilst the children played and got to know the centre and playworkers, parents used our kitchen facilities to prepare and share food from their homelands and we enjoyed communal snacks. Families were later rehoused into more suitable accommodation and after attending the family sessions, parents developed confidence to allow their children to attend the play centre unaccompanied during usual opening hours.

On a personal level being involved in this project has given me an experience you cannot buy. I have been involved in discussions with a community that not many people understand and have been given the opportunity to work with their children on a one-to-one basis. We experience some issues, but not in terms of the integration. The issues are more in relation to normal children's behavior and learning how to interact with each other as individuals. 


\section{Policy Maker Tool 3 \\ Working together to \\ provide for the right to \\ play in situations of crisis}

Children's wellbeing, development, and their essential enjoyment of childhood, are affected by their opportunities to play. The co-operation of many different professionals is needed to ensure an effective approach.

The UN Committee on the Rights of the Child calls for cross-departmental collaboration in national and municipal government. Through General comment No. 17, the Committee asserts:

"Planning for play, recreation and cultural and artistic activities requires a broad and comprehensive approach involving cross-departmental collaboration and accountability between national, regional and municipal authorities. Relevant departments include not only those dealing directly with children, such as health, education, social services, child protection, culture, recreation and sports, but also those concerned with water and sanitation, housing, parks, transport, environment and city planning, all of which impact significantly on the creation of environments in which children can realize their rights under article 31;"

(UN Committee on the Rights of the Child, 2013: para.58c)

The best interests of children must be the primary concern in making decisions that may affect them. All adults should do what is best for children. When adults make decisions, they should think about how their decisions will affect children. The Convention on the Rights of the Child makes it clear that this particularly applies to budget, policy and lawmakers.

Undertaking an assessment will identify the impact that a decision can have on a child or a group of children affected by it.

\section{What might be included in a play impact assessment?}

- Description of the proposed measure (legislation/policy/project)

- Identify how the measure affects (or might affect) children's opportunity to play

- Identify how the proposed measure is affected by, or affects, other current government/ activities/policy
- Identify problems or gaps in information and expertise that the proposal entails

- Children and family viewpoints on the proposal

- Steps to address any adverse effects

- Guidelines on how the measure should be monitored

- Evaluation of the effect the decision had. 


\section{Policy Maker Tool 4 \\ Self-assessment tool: providing an optimum environment for play}

The Committee on the Rights of the Child asserts that children have a spontaneous urge to play and participate in recreational activities and will seek out opportunities to do so in the most unfavourable environments. However, certain conditions need to be assured, in accordance with children's evolving capacities, if they are to realise their rights under article 31 to the optimum extent.

The Features column: sets out the features of an optimum environment as set out in General comment No. 17 (para. 32)

Red (O), Amber (1), Green (2) (RAG) status is a tool to communicate status quickly and effectively. You can use the colour or number system.

\section{RAG Status}

\begin{tabular}{|c|c|}
\hline Criteria not met. & $\mathrm{O}$ \\
\hline Criteria partially met. & 1 \\
\hline Criteria fully met. & 2 \\
\hline
\end{tabular}

RAG status column: can be used by an organisation to show its assessment of whether that feature is fully met, partially met, or not met.

Evidence to support strengths column: should be used to provide the reason for the chosen status and how the evidence is held.

Shortfall column: should be used to explain the areas in which the play space/opportunities/ provision do not fully meet the criteria.

Identified Action column: should be used to show the intended action to rectify shortfalls. 


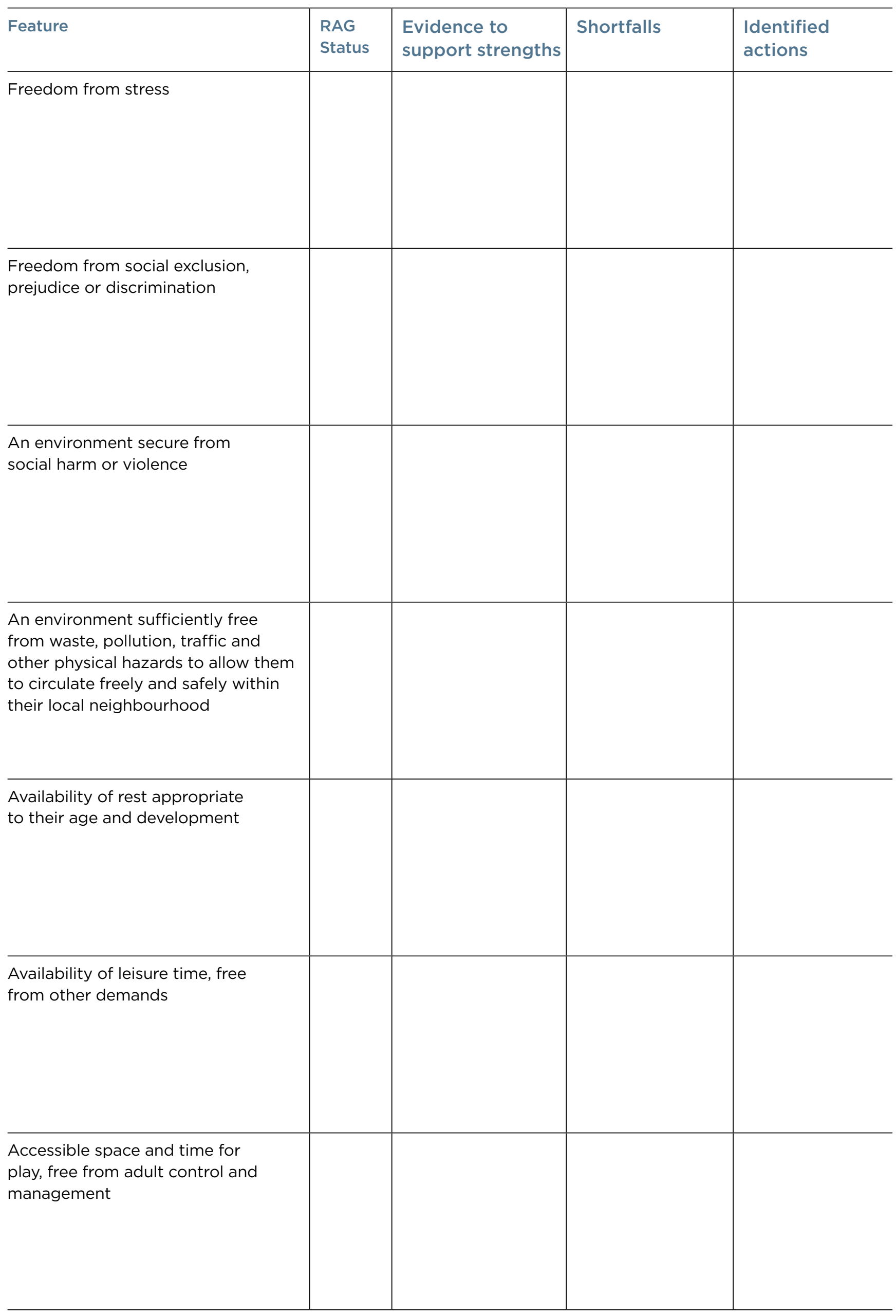




\begin{tabular}{|c|c|c|c|c|}
\hline Feature & $\begin{array}{l}\text { RAG } \\
\text { Status }\end{array}$ & $\begin{array}{l}\text { Evidence to } \\
\text { support strengths }\end{array}$ & Shortfalls & $\begin{array}{l}\text { Identified } \\
\text { actions }\end{array}$ \\
\hline $\begin{array}{l}\text { Space and opportunities to play } \\
\text { outdoors unaccompanied in a } \\
\text { diverse and challenging physical } \\
\text { environment, with easy access to } \\
\text { supportive adults, when necessary }\end{array}$ & & & & \\
\hline $\begin{array}{l}\text { Opportunities to experience, } \\
\text { interact with and play in natural } \\
\text { environments and the animal worl }\end{array}$ & & & & \\
\hline $\begin{array}{l}\text { Opportunities to invest in their ow } \\
\text { space and time so as to create ano } \\
\text { transform their world, using their } \\
\text { imagination and languages }\end{array}$ & & & & \\
\hline $\begin{array}{l}\text { Opportunities to explore and } \\
\text { understand the cultural and artisti } \\
\text { heritage of their community, } \\
\text { participate in, create and shape it }\end{array}$ & & & & \\
\hline $\begin{array}{l}\text { Opportunities to participate with } \\
\text { other children in games, sports } \\
\text { and other recreational activities, } \\
\text { supported, where necessary, by } \\
\text { trained facilitators or coaches }\end{array}$ & & & & \\
\hline $\begin{array}{l}\text { Recognition by parents, teachers } \\
\text { and society as a whole of the } \\
\text { value and legitimacy of the rights } \\
\text { provided for in article } 31\end{array}$ & & & & \\
\hline
\end{tabular}




\section{Bibliography}

Bartlett, S. \&. Iltus, S. (2007). Making Space for Children: Planning for post-disaster reconstruction with children and their families., Save the Children UK, Save the Children Sweden - South and Central Asia Region.

Bull-Kamanga, L., Diagne, K., Lavell, A., Leon, E., Lerise, F., MacGregor, H., Maskrey, A., Meshack, M., Pelling, M., Reid, H. 2003. From everyday hazard to disasters: the accumulation of risk in urban areas. Environment and Urbanisation 51 (1), pp. 193-204

Chatterjee, S. (2005). Children's friendship with place: A conceptual inquiry. Children, Youth and Environments, 15(1), pp. 1-26.

Chatterjee, S. (2006). Children's friendship with place: An exploration of environmental child friendliness of children's environments in cities. North Carolina State University

Else, P. and Sturrock, G. (1988) The Playground as Therapeutic Space: Playwork as Healing, in: Proceedings of the IPA/USA Triennial National Conference, June 1998, Colorado, Play in a Changing Society: Research, Design, Application

Hughes, B. (1996) A Playworker's Taxonomy of Play Types. London: PLAYLINK

Hughes, B. (2001) The First Claim... a framework for playwork quality assessment. Cardiff: Play Wales

International Play Association (2010)

IPA Global Consultations on Children's Right to Play Report. Faringdon: IPA

International Play Association, Play Rights, July 2015 Issue 1:15

Kyttä, M. (2002). Affordances of children's environments in the context of cities, small towns, suburbs and rural villages in Finland and Belarus. Journal of Environmental Psychology, 22(1e2), pp.109-123.

http://dx.doi.org/10.1006/jevp.2001.0249
Kyttä, M. (2004). The extent of children's independent mobility and the number of actualized affordances as criteria for child-friendly environments. Journal of Environmental Psychology, 24(2), pp.179-198. http://dx.doi.org/10.1016/S0272- 4944(03)00073-2

Lester, S. and Russell, W. (2010) Children's Right to Play: An examination of the importance of play in the lives of children worldwide. Working Paper No. 57. The Hague, The Netherlands: Bernard van Leer Foundation

Nicholson, S. (1972) The Theory of Loose Parts. An important principle for design methodology. Studies in Design Education Craft \& Technology, 4 (2), p.5-14

Play Wales (2008) P3-Playwork Principles into Practice Level 2 - Award learning materials. Cardiff: Play Wales

Save the Children, 2008. Child Friendly Spaces in Emergencies: A handbook for Save the Children staff. [Online]. Available at: https://resourcecentre.savethechildren.net/ library/child-friendly-spaces-emergencieshandbook-save-children-staff [Accessed 2103 2017].

UNCDSN. (2016) Indicators and a Monitoring Framework. Retrieved from Sustainable Development Solutions Network: http://indicators.report/indicators/i-6

UN Committee on the Rights of the Child (2013) General comment No. 17 (2013) on the right of the child to rest, leisure, play, recreational activities, cultural life and the arts (art. 31). Geneva: Committee on the Rights of the Child

UN General Assembly, Convention on the Rights of the Child, 20 November 1989, United Nations, Treaty Series, vol. 1577, p. 3, available at: http://www.refworld.org/docid/3ae6b38fo.html 


\section{Resources and further reading}

Children's right to play and the environment

http://ipaworld.org/childrens-right-to-play-and-the-environment

Under the Same Sky: Toolkit of creative activities for children to explore their everyday environments http://ipaworld.org/news/under-the-same-sky

Children's right to play - a booklet for a richer understanding of children's right to play http://www.ipascotland.org/wp-content/uploads/2016/12/

IPA-SCOTLAND-CHILDRENS-RIGHT-TO-PLAY-A5-BOOKLET-Web.pdf

Loose Parts Play - a toolkit

http://www.inspiringscotland.org.uk/media/58451/Loose-Parts-Play-web.pdf

Design for Play - A guide to creating successful play spaces

http://playengland.org.uk/media/70684/design-for-play.pdf

Managing Risk in Play Provision

http://www.playengland.org.uk/media/172644/managing-risk-in-play-provision.pdf

Play Wales publications and library

http://www.playwales.org.uk/eng/publications 
IPA's purpose is to protect, preserve and promote the child's right to play as a fundamental human right.

Article 31 of the United Nations Convention on the Rights of the Child

"Every child has the right to rest and leisure, to engage in play and recreational activities appropriate to the age of the child and to participate freely in cultural life and the arts.

Member governments shall respect and promote the right of the child to participate fully in cultural and artistic life and shall encourage the provision of appropriate and equal opportunities for cultural, artistic, recreational and leisure activity."
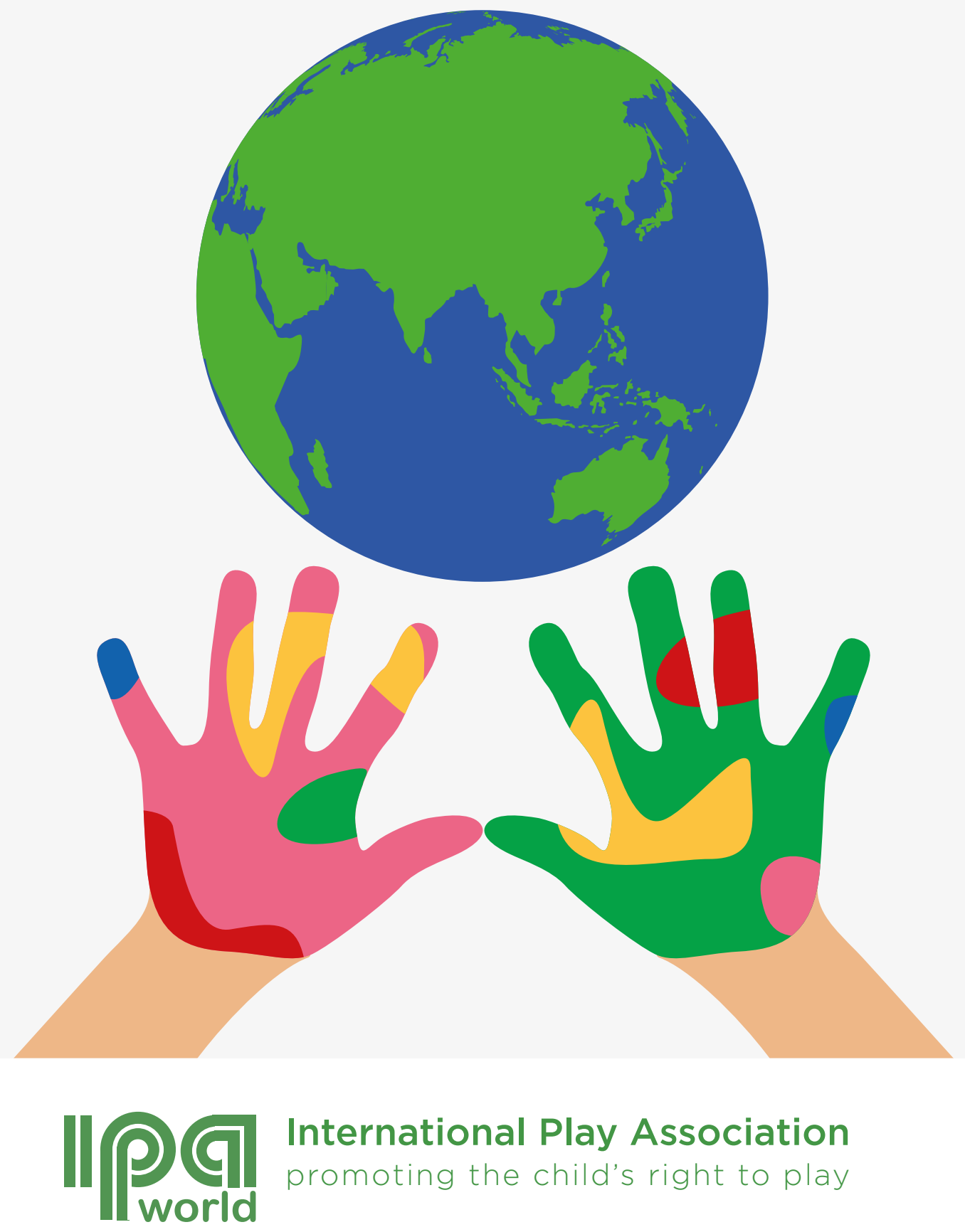

w: www.ipaworld.org e: secretary@ipaworld.org 